\title{
Multiple global change impacts on parasitism and biocontrol services in future agricultural landscapes
}

Article

Accepted Version

Creative Commons: Attribution-Noncommercial-No Derivative Works 4.0

Monticelli, L. S., Bishop, J. ORCID: https://orcid.org/00000003-2114-230X, Desneux, N., Gurr, G. M., Jaworski, C. C., McLean, A. H. C., Thomine, E. and Vanbergen, A. J. (2022) Multiple global change impacts on parasitism and biocontrol services in future agricultural landscapes. Advances in Ecological Research, 65. pp. 245-304. ISSN 0065-2504 doi: https://doi.org/10.1016/bs.aecr.2021.10.002 Available at https://centaur.reading.ac.uk/101140/

It is advisable to refer to the publisher's version if you intend to cite from the work. See Guidance on citing.

To link to this article DOI: http://dx.doi.org/10.1016/bs.aecr.2021.10.002

Publisher: Elsevier

All outputs in CentAUR are protected by Intellectual Property Rights law, including copyright law. Copyright and IPR is retained by the creators or other copyright holders. Terms and conditions for use of this material are defined in the End User Agreement. 


\section{CentAUR}

Central Archive at the University of Reading

Reading's research outputs online 
Suggested title: Multiple global change impacts on parasitism and biocontrol services in future agricultural landscapes

Monticelli Lucie S..$^{*}$, Bishop Jacob ${ }^{2}$, Desneux Nicolas ${ }^{1}$, Gurr Geoff M. ${ }^{3}$, Jaworski Coline C. ${ }^{4,5}$, McLean Ailsa H. C. ${ }^{4}$, Thomine Eva ${ }^{6}$, Vanbergen Adam J. ${ }^{7}$

1: Université Côte d'Azur, INRAE, CNRS, UMR ISA, 06000 Nice, France

2: School of Agriculture, Policy and Development, University of Reading, Reading, Berkshire, UK

3: School of Agricultural and Wine Sciences, Charles Sturt University, Orange, NSW, 2800,

Australia

4: Department of Zoology, University of Oxford, Oxford, UK

5: Department of Zoology, University of Cambridge, Cambridge CB2 3EJ, UK

6: L@blsen, Isen Yncrea Ouest, Brest

7: Agroécologie, INRAE, Univ. Bourgogne Franche-Comté, Dijon, France

* Corresponding author: lucie.monticelli@gmail.com

j.bishop@reading.ac.uk; nicolas.desneux@inrae.fr; ggurr@csu.edu.au;

jaworskicoline@yahoo.fr; ailsa.mclean@zoo.ox.ac.uk; eva.thomine@gmail.com;

Adam.Vanbergen@inrae.fr 


\section{ABSTRACT:}

2 Parasitoids are a significant mortality factor in the population dynamics of many arthropods 3 involved in key ecological processes such as herbivore-plant and predator-prey interactions. 4 Parasitoids are therefore widely used in biocontrol programs. Global change phenomena 5 influence these natural and anthropocentric roles of parasitoids and here we review the effects 6 of the main drivers and their interplay. Land use intensification modifies landscape structure 7 and elevates agroecosystem loads of fertilizers and pesticides creating risks for parasitism 8 and loss of biocontrol services. Climate change can affect parasitoids directly, affecting 9 physiology and survival, or indirectly via phenological and other effects (plant chemistry, 10 herbivore-induced plant volatiles HIPVs) on their hosts, endosymbionts and plants. Biological 11 invasions have the potential to modify native host-parasitoid systems and elevate risk of novel 12 pest dynamics, requiring restoration of biocontrol. The interplay between these global change 13 drivers may thus exacerbate the overall risk to parasitism in future agricultural landscapes. To 14 make more accurate predictions, future studies could focus on the impact of interacting global 15 change drivers on parasitoids and the biocontrol services they provide. Moreover, host and 16 parasitoid specificity appear to be a key driver in assessing the effects of global change on 17 parasitoids.

19 KEY WORDS: Parasitoid, land use intensification, climate change, biological invasion, 20 ecological interactions, sustainable agriculture, pest management, host specificity. 
INTRODUCTION:

The magnitude, spatial extent and rapidity of current environmental changes is unprecedented. The main global changes that threaten biodiversity and have the potential to disrupt herbivore-plant, predator-prey and parasitoid-host interactions are land use intensification, climate change and biological invasions (Early et al. 2016; Foley et al. 2005; IPBES 2019; Laliberté et al. 2010; Pecl et al. 2017; Pimm and Raven, 2000; Sala et al. 2000; Vanbergen et al. 2020; Walther et al. 2002). Aside from disruption to the natural world, global change phenomena threaten the biodiversity, ecosystem functions and services upon which humanity depends (IPBES 2019).

Changing land-use patterns can result in conversion (i.e., altering natural habitats for human use) or intensification (e.g., greater intensity and/or frequency of disturbance, increased use of external inputs; Foley et al. 2005) (Figure 1). Despite the negative effects of land-use intensification, the practice has expanded globally with an increase of $64 \%$ in arable production, 57\% in livestock numbers and 112\% in built-up areas until 2040 (van Asselen and Verburg 2013). Climate change leads to an increase in global average temperature and increases in the frequency and duration of drought events or the frequency of catastrophic and unpredictable events (IPCC 2021). Global warming induces shifts in phenology, physiological changes and range shifts in species (Walther et al. 2002) (Figure 1). Ectothermic species such as insects, "the little things that run the world" (Wilson, 1987), must therefore respond to these large temperature variations and extreme climatic events by adapting and/or moving, or by going extinct. Finally, human-induced biological invasions can lead to the collapse of classical biogeographic regions (Capinha et al. 2015) and considerable social, economic and ecological damage (Blackburn et al. 2011), altering ecosystems and endangering food security (Schweiger et al. 2010; Ziska et al. 2011) (Figure 1).

\section{[Insert Figure 1 here]}

Figure 1. Impacts on the (a) biocontrol services provided by parasitoids of (b) climate change, (c) land use intensification and (d) biological invasions. These global change drivers impact on, directly and indirectly, the primary producer (non-crop or crop plant) and secondary (insect herbivores or pests) and tertiary (parasitoids) trophic levels. HIPVs: herbivore-induced plant volatiles. Images sourced from thenounproject.com (CC-BY: Ayumi Aya; Baboon designs; Carpe Diem; Denimao; Megan Strickland; Phạm Thanh Lộc; Varvarvarvarra; Yu luck) and following websites: https://www.google.fr/maps/.

Insect parasitoids have a life cycle that is divided into parasitic larval stages and a freeliving adult stage. The female parasitoid in the adult stage deposits an egg inside or outside its host (typically another insect or arthropod) and the resulting larva develops by feeding on the body of the host, resulting in its death. They are considered important natural enemies of 
levels, such as insect herbivores (Heimpel and Miles, 2017; Jervis 2005). The effectiveness of parasitoids as biocontrol agents has been demonstrated against a large number of different pest invertebrates (Heimpel and Mills, 2017), and are responsible for a large number of biocontrol successes from an economic and environmental point of view (LaSalle 1993). In addition, parasitoids often demonstrate high host specificity since they attacks hosts mainly from the same family, thus reducing the ecological risks of introducing a biocontrol agent into a new environment (classical biocontrol) (Heimpel and Mills, 2017). Therefore, the hosts alone represent both the food source and physiological environment of the developing immature parasitoids. The effects of global changes on host fitness and populations may then, in turn, be transmitted up the food chain to influence parasitoids. Parasitoids are haplodiploid, having lower standing genetic variation and mutation rates compared to their hosts (which are typically diploid) in responding to global changes (Biale et al. 2020; Le Lann et al. 2021; Smith and Shaw, 1980).

Given the magnitude of global change phenomena, and the importance of parasitoids in the natural world and in biological pest control, here we review the literature to assess the likely impacts of land use intensification, climate change and biological invasions to predict likely community- and individual-level effects on host-parasitoid interactions and biocontrol.

\section{1 - AGRICULTURAL INTENSIFICATION}

Intensification of land use, characterised by increased use of external inputs, frequent disturbance and ecosystem homogenisation, is a major driver of worldwide decline in biodiversity and ecosystem degradation (Foley et al. 2005). Land use intensification effects on the environment (e.g., vegetation, habitat resources) drive changes in pest and parasitoid populations from the individual- to community-level. In this section, we consider how conventional agricultural intensification through external input use (pesticide and nitrogen) and crop/landscape management impact pests and their parasitoids (primary and secondary) (Figure 2).

Conventional agricultural intensification can occur both at local and landscape scales. At the local scale, the intensification of management results from the adoption of short crop rotations, increased monocultures, increased inputs of fertilizers and pesticides, deep ploughing, increased field sizes and high levels of mechanisation (Tscharntke et al. 2005). As a consequence, where these practices are extended to a large number of fields, the entire landscape will be modified with widespread conversion of perennial and natural habitat to crops, habitat fragmentation and loss of landscape complexity in space and time (Tscharntke et al. 2005). This correlation between local practice and landscape simplification means it is important to consider the effect of agricultural intensification on pests, parasitoids and their interactions. 
[Insert Figure 2 here]

Figure 2. Impacts of conventional agricultural intensification on plant-host-insect-parasitoidhyperparasitoid individuals and food web stability and diversity. Direct and indirect as well as positive or negative effects of landscape simplification and intensive use of external inputs (pesticides and nitrogen fertilizer) are illustrated. Images sourced from thenounproject.com (CC-BY: Carpe Diem; Megan Strickland; Phạm Thanh Lộc; Yu luck) and following websites: monsafety.wordpress.com; morningagclips.com; https://www.google.fr/maps/.

\subsection{Direct and indirect effects of external inputs on host-parasitoid interactions}

\subsubsection{Impact of pesticides}

Agriculture relies heavily on chemical pesticides to control crop pests in a cost-effective way (Cooper and Dobson, 2007). However, these substances have non-negligible adverse effects such as lethal and sublethal impacts on non-target organisms, development of pest resistance and secondary pest outbreaks, as well as pollution of water, soil and bioaccumulation of residues in food chains (Cloyd 2012; Desneux et al. 2007; Pinheiro et al. 2020; Weinzierl 2008). The sensitivity of parasitoids to plant protection products depends on their biology (guild, developmental stage, sex, age), the pesticide regime (type and dose of pesticide used, the method and timing of application) and the mode of action of the active substances (Cloyd 2012; Desneux et al. 2006a; 2006b). Among chemical pesticides, insecticides such as organophosphates and pyrethroids are generally more toxic (Ohta and Takeda, 2015; Pinheiro et al. 2020) than herbicides and biopesticides, which have less impact on parasitoid survival and fecundity (Khan and Ruberson, 2017; Pinheiro et al. 2020).

Pesticides can affect parasitoids through direct contact with spray droplets or treated surfaces (Krischik et al. 2007; Longley and Jepson, 1996; Stapel et al. 2000), or mediated by plant uptake of pesticides in the soil or pore water that can lead to cumulative bottom-up effects on higher trophic levels (Kampfraath et al. 2017; Mullin and Croft 1985). Persistent pesticide contamination of host and parasitoid food sources (pollen, nectar, and host exudates such as honeydew) required for survival, egg maturation in synovigenic females, and reproduction (Benelli et al. 2017; Cowles and Eitzer, 2017; Jervis and Kidd, 1996; Pinheiro et al. 2020), significantly increases the risk of exposure and harm to parasitoids (Pinheiro et al. 2020).

Direct and indirect (via their hosts) contact with pesticides can alter parasitoid host locating and food foraging behaviors in a number of ways (Desneux et al. 2007; Kampfraath et al. 2017; Wang et al. 2016). Pesticides induce modifications of the chemical constituents of plants, thereby affecting the nutritional value or attractiveness of pollen or nectar foods to the free-living adult parasitoids (Hervé et al. 2014; Serra et al. 2015). Pesticides can interfere with parasitoid behaviours reliant on chemical signals. Pesticide exposure can reduce the host location ability of parasitoids by disrupting the detection of kairomones involved in olfactory orientation during foraging (Desneux et al. 2004a; 2004b) or communication using sex pheromones (Desneux et al. 2004b; Stapel et al. 2000; Tappert et al. 2017). The use of 
pyrethroids, in particular, can impair the mobility and orientation ability of parasitoids when searching for food sources or host plants (Schoonhoven et al. 2005).Greater aggregation of parasitoids (Aphidius spp. Braconidae, Hymenoptera) on crop plants and higher parasitism rates were observed in the absence of pesticide use, implying repellency from treated areas (Longley and Jepson, 1996) and a lowering of parasitoid exposure (to some extent) to pesticides (Desneux et al. 2005).In some cases, however, parasitoid adults exposed to residual pesticide doses retain their ability to orient towards host odors (Desneux et al. 2006a; 2006b), or these abilities may be recovered after sublethal exposure (Desneux et al. 2004c; Longley and Jepson, 1996).

Exposure to pesticides can also modify the survival or physiological function of parasitoids. Direct and indirect contact with pesticides can reduce survival at various developmental stages (Bueno et al. 2008; Fontes et al. 2018; Khan and Ruberson, 2017). Adult parasitoids exposed to pesticides suffer increased short-term mortality (Asadi et al. 2019; Bayram et al. 2010; Cheng et al. 2021; Ohta and Takeda, 2015). For example, the pesticide Metomil reduces the survival of Trichogramma pretiosum (Hymenoptera: Trichogrammatidae) eggs, larvae, and pupae by $96 \%, 91 \%$, and $67 \%$, respectively, with only $5 \%$ of parasitoids exposed to pesticides being viable (Bueno et al. 2008). Negative sublethal effects have been seen on parasitoid larval and pupal development as well as on fertility, sex ratio or oviposition ability (Cheng et al. 2021; D'Ávila et al. 2018; Kampfraath et al. 2017; Vianna et al. 2009). Aphidius ervi, following exposure to pesticides, demonstrated uncoordinated and irreversible female ovipositor extrusion leading to failure of parasitism (Desneux et al. 2004c). Pesticides can modify host immune defences, for example, exposure of the host Drosophila melanogaster to the pesticide Dieldrin leads to a $25 \%$ reduction in immune defenses against the parasitoid Leptopilina boulardi (Delpuech et al. 1996), which could affect, in turn, the development of immature parasitoids.

The lethal and sublethal effects of pesticides on individuals and populations may lead to modifications of the structure of the arthropod community. Pesticide use by disrupting topdown control in an agroecosystem may promote secondary pest outbreaks (Guedes et al. 2017, 2016; Lu et al. 2012; Zhao et al. 2017, 2016). This might be due to altered community dynamics as seen in the case of imidacloprid application that modulated competition among aphid species to induce a shift in both aphid and natural enemy species dominance (Mohammed et al. 2019). In Banana plantations, parasitoid abundance and species richness were inversely related to rates of insecticide application (Matlock and de la Cruz, 2002). Deltamethrin treatment resulted in initial reductions of aphid, primary parasitoid and hyperparasitoid populations by $78 \%, 90 \%$ and $47 \%$ respectively (Longley et al. 1997). Nonetheless, populations of primary and secondary parasitoids were able to re-invade treated ecosystems, suggesting the existence of reservoir areas hosting natural enemy populations, 
and parasitoids may limit aphid population growth soon after a deltametrin application (Desneux et al. 2005).

\subsubsection{Impact of nutrient inputs:}

Because of its importance to plant productivity, fertilizers supplying Nitrogen $(\mathrm{N})$ are frequently used in agricultural production (McNeill and Southwood, 1978; Stiling and Moon, 2005). Fertilization can modify plant primary and secondary metabolites causing a variety of bottomup effects on tritrophic, parasitoid interactions via a number of mechanisms (Chen et al. 2010; Pekas and Wackers, 2020; Sarfraz et al. 2009). Fertilisation tends to generate bottom-up increases in the strength or frequency of herbivore-plant, predator-prey and parasitoid-host interactions, for example (e.g., De sassi et al. 2012; Moon and Stiling, 2002, 2000; Tylianakis et al. 2008) (Figure 2).

Many insect herbivores are able to distinguish between host plants of high and low nutritional quality and tend to prefer fertilized to unfertilized host plants for oviposition (Chen et al. 2008a, 2004; Prudic et al. 2005). Plant emissions of herbivore-induced plant volatiles (HIPV) are a well-known mechanism by which plants signal to and recruit natural enemies to attack herbivores. Parasitoids tend therefore to fly more frequently towards host-damaged plants e.g., Cotesia marginiventris (Cresson) (Röse et al. 1998), Microplitis croceipes (Cresson) (Röse et al. 1998) and Cardiochiles nigriceps Viereck (De Moraes et al. 1998). Nitrogen levels can alter positively, negatively or can have no effects on the production and release of these volatiles depending upon the plant (Chen et al. 2010). Well-nourished plants emitted several HIPVs enabling parasitoid recruitment in contrast with nitrogen-deficient plants (Becker et al. 2015; Chen et al. 2010; Han et al. 2014; Ibrahim et al. 2008; Winter and Rostás, 2010). By contrast, the amount of volatile released decreased when $\mathrm{N}$ concentration in the nutrient solution increased in corn (Zea mays var Delprim) (Schmelz et al. 2003) and did not vary in tobacco (Nicotiana attenuata) (Lou and Baldwin, 2004).

Phytophagous insects that feed on well-nourished host plants exhibit higher growth rates, higher efficiency of food use, higher fecundity, and higher abundance (Awmack and Leather, 2002; Chen et al. 2010, 2004; Karowe and Martin, 1989; Mattson 1980; Moon and Stiling, 2000; Weibull 1987; Zhao et al. 2015). An increase in nitrogen input may therefore improve the nutritional quantity (enhanced size of host) or quality of the host supporting the immature developing parasitoid and/or synovigenic species that require host feeding (i.e., feeding on host body fluids) for egg development, such effects of $\mathrm{N}$ may thus increase levels of parasitism (e.g., Chen et al. 2010; Gharekhani et al. 2020; Moon and Stiling, 2000; Pekas and Wackers, 2020; Sarfraz et al. 2009). High N concentration in the soil may also disrupt the herbivore immune system promoting parasitoid development. For instance, high nitrate concentration in the soil impairs the immune system of Myzus persicae allowing the parasitoid 
212 Diaeretiella rapae (Hymenoptera: Braconidae) to emerge at rates 1.5 times higher than when

213 the nitrate concentration is low (Chesnais et al. 2016). A high nitrogen concentration may,

214 however, also reduce parasitism rates. The parasitism rate of Diadegma insulare when

215 encountering its host Plutella xylostella decreased at high $\mathrm{N}$ concentration, despite increased

216 parasitoid survival rates, suggesting no role for the host immune system in lower parasitisation

217 (Sarfraz et al. 2009).

218 Some plant allelochemicals that function as defensive compounds are produced in 219 greater quantities in well-fertilized conditions (Cipollini and Bergelson, 2001; Lou and Baldwin, 220 2004) and are sequestered in the hemolymph of herbivorous insects. Development times and 221 survival rates of adult parasitoids feeding on these insects and/or immature larvae developing 222 in these hosts may therefore be altered (Campbell and Duffey, 1979; Duffey et al. 1986; van 223 Emden 1995; Kester and Barbosa, 1991; for a review, see Turlings and Benrey, 1998; but see 224 Schuler et al. 1999). For example, Lou and Baldwin (2004) noted that $\mathrm{N}$ addition increased nicotine production in tobacco. Manduca sexta, which is a specialist herbivore of tobacco, can sequester nicotine in its hemolymph with no ill-effects (Self et al. 1964). The parasitoid Cotesia congregata is, by contrast, more sensitive to nicotine and larval survival is reduced (Barbosa et al. 1991; Parr and Thurston 1972; Thorpe and Barbosa 1986). Nevertheless, the typical effect of most constitutive secondary metabolites involved in plant defense are negatively or even unrelated to $\mathrm{N}$ levels (Cipollini and Bergelson, 2001; Darrow and Bowers, 1999; Dudt and Shure, 1994; Hemming and Lindroth, 1999; Hol et al. 2003; Prudic et al. 2005; Stout et al. 1998; Wall et al. 2005), and parasitoids that feed on hosts developing on well-nourished plants generally perform better.

234

\subsection{Landscape simplification}

236

The pursuit of food productivity and efficiency, and the widespread adoption of conventional agricultural intensification has come with the costs of ecological homogenization, loss of biodiversity and ecosystem services, invasive pest outbreaks, and rising human health issues (Baude et al. 2019; IPBES 2019; Larsen and Noack, 2021). Landscape simplification arising from habitat conversion and adoption of industrial crop monocultures to increase the productivity of land is a globally widespread phenomenon (Baude et al. 2019; Larsen and Noack, 2021). As an example, cereals occupy most of the arable lands in the EU, with 121 million hectares planted in 2019 , in comparison to the 60 million hectares for all other crops.

Landscape complexity is a combination of composition and configuration of different habitats (Fahrig et al. 2011), and both these aspects have been shown to be important for natural enemies and biocontrol (Haan et al. 2019; Karp et al. 2018). A highly cropped landscape is often defined as a poorly diversified landscape (i.e., less complex landscape) compared to a landscape with a high proportion of natural and semi-natural habitats (Bianchi 
et al. 2006; Karp et al. 2018; Veres et al. 2013). Landscapes with high configuration complexity can be defined as land having high connectivity between the different habitats, reduced patch size, increased richness of land cover types and increased irregularity of patch shapes (Dominik et al. 2018; Nelson and Burchfield, 2021).

Such differences in landscape compositional or configurational complexity are another factor affecting parasitoid biocontrol efficiency (Jonsson et al. 2012) (Figure 2). This is because highly simplified landscapes lack the diversity of ecological resources to fulfil the trophic needs (host and non-host) and life-histories of parasitoids. Parasitoids need diversified food sources as they can be pollinators during their adult stage and carnivores during their larval stage (Gurr et al. 2017). Consequently, more diverse and structurally complex landscapes are hypothesised to harbour sufficient resources for different parasitoid species and life-histories in space and time, with potential gains in biocontrol efficacy in crop fields. For example, a landscape dominated by wheat in monoculture risks a sudden post-harvest drop in parasitoid populations and potential biocontrol due to a lack of spatial and temporal connections to alternative food sources (e.g., hosts or floral resources in semi-natural habitats or other crops). The implication is therefore that in highly simplified, intensively managed landscapes or habitats the efficacy of biocontrol will be reduced (Schellhorn et al. 2015). Conversely, greater habitat compositional and configurational complexity may promote parasitoid populations and high biocontrol efficacy (Dominik et al. 2018). The need for diversified food sources to support parasitoid life cycles (Gurr et al. 2017) can be met by agricultural land management. Plant diversity underpinning both host and parasitoid resources can be manipulated at the field (crop types), farm (crop diversity, field margin diversity, habitat composition and connectivity, field size and shape) and landscape (landscape complexity, semi-natural habitat cover and habitat composition and configuration) scale (Gillespie et al. 2016).

In this section, we focus on the importance of agricultural landscape complexity on parasitoids and, where evidence allows, their food web interactions. We detail the impact of simplification of habitat composition and configuration on parasitoids.

\subsubsection{Effect of habitat composition simplification on parasitoids}

279 Parasitoid trophic dependence on their hosts means there can be a strong density-dependent link to host population dynamics (Gagic et al. 2012). Such a simple response may, however, be modulated by the composition of the landscape and the complexity of the host-parasitoid food-web. Agricultural landscape simplification can reduce parasitoid abundances (Letourneau et al. 2012) and parasitism efficacy (Elliott et al. 2018; Gagic et al. 2012; Grab et al. 2018; Plećaš et al. 2014). This lowering of population size or biocontrol is associated with 
landscapes that provide overwintering sites, pollen and nectar sources, or alternative prey and hosts that are key to maintaining parasitoid populations and biocontrol efficacy (Gillespie et al. 2016). The abundance of the Tachinidae, a common guild of parasitoid flies, increases with the presence of semi-natural habitats and perennial vegetation but is negatively correlated to the proportion of annual crop cover (Letourneau et al. 2012). Maintaining semi-natural habitats and perennial plants in landscapes is likely to be crucial for maintaining the populations of parasitoids that are active in adjacent short-cycle crop fields (Letourneau et al. 2012). Compositional complexity of agricultural landscapes is also important as parasitoids use different habitat types during the year and frequently disperse among habitats. Proximity of different habitats is thus crucial for the spillover of parasitoids and biocontrol services from semi-natural to cropped areas (Elliott et al. 2018). Along with greater parasitism efficacy in complex landscapes, the proportion of pests is often lower due to dilution or reduced apparency of their food resources in the more compositionally complex landscapes and is associated with higher yields (Grab et al. 2018, but see Plećaš et al. 2014). This suggests that there may be a direct benefit of landscape diversification on yields and farm incomes through reduction in pest pressure.

Agricultural landscape simplification through cropland expansion can also increase parasitoid abundance and parasitism rates (Hawro et al. 2017; Zhao et al. 2015), although effects vary according to the ecology or life-history of different species or functional groups. Where host density responds positively to crop monocultures due to a concentration of plant resources (e.g., aphid pests of cereals) there may be a corresponding density-dependent primary parasitoid response in a tri-trophic interaction (Gagic et al. 2012; Hawro et al. 2017). Agricultural simplification may therefore impact parasitoid food webs through bottom-up forces transmitted along the links in the plant - host insect - parasitoid - hyperparasitoid food web (Lohaus et al. 2013). Agricultural intensification can increase the complexity of aphidparasitoid food webs (e.g., interaction evenness), in contrast to the hypothesis that organic and low intensity farming preserve species richness and food web complexity (Lohaus et al. 2013). For example, parasitoids able to overwinter in the oilseed rape crops are unaffected by changes in the area of surrounding semi-natural habitat, highlighting how specific ecology dictates parasitoid responses to landscape-scale habitat complexity (Berger et al. 2018; Haan et al. 2020).

Finally, effects of landscape compositional simplification on parasitoids can be positive, negative or idiosyncratic. In highly-simplified landscapes, host(aphid)-parasitoid foodwebs can be more complex, but less stable due to high levels of temporal change in the hostparasitoid network in intensively-managed fields, likely due to bottom-up fluxes in aphid abundance (Gagic et al. 2014, 2012). Food webs stability can therefore be decreased in landscapes with high agricultural intensification, although the overall richness of parasitoids 
may remain high in intensified agricultural lands (Gagic et al. 2012). High levels of agricultural intensification can produce distinct parasitoid species assemblages where the constituent species are low-dispersing specialised parasitoid leading to a lack of connectivity between local populations and higher species turnover (Gagic et al. 2014). Different effects of landscape simplification on parasitoids according to traits such as dispersal capacity complicate the formation of clear predictions (Gagic et al. 2014). Interestingly, parasitism rates and hyperparasitism rates seem higher in fields with high landscape (Gagic et al. 2012). The response of host-parasitoid interactions and parasitism rates to landscape compositional complexity are therefore complex and variable (Haan et al. 2019). Much of this can be explained by variation in species assemblage composition, richness or abundance between regions and regional differences in management practices or intensity (Hawro et al. 2015; Plećaš et al. 2014; Thies et al. 2011). Differences in the relative strength of bottom-up and top-down forces on the different trophic levels (host - parasitoid - hyperparasitoid) are another factor that can shape the impact of landscape composition on abundance and parasitism (Ulina et al. 2019).

338

\subsubsection{Effect of habitat configuration simplification on parasitoids}

340 Habitat configuration at the landscape scale can have a significant impact on parasitoids (Berger et al. 2018; Dominik et al. 2018; Haan et al. 2020; Martin et al. 2016; Ulina et al. 2019). Parasitoid abundance tends to be greater in fields embedded in fragmented landscapes with high edge densities. The configurational effect of a landscape can reduce the impact of landscape composition (Haan et al. 2020). In a study led in oilseed rape (OSR) fields, proximity to the forest favoured agricultural pest colonisation of the crop from nearby forest where they overwinter, but there was no concomitant spillover of parasitoid populations. Consequently, the larger the OSR field and the greater the distance to the forest edge, the lower the pest density and the greater the biocontrol efficacy of the more mobile parasitoids to locate and suppress the pest population (Berger et al. 2018). Additionally, the parasitoids were able to overwinter in the OSR field (Berger et al. 2018) and do not need shelter or alternative food from the forest. A consequence of these differential ecological patterns and processes is that host-parasitoid food webs were more asymmetrical in larger fields (Berger et al. 2018). However, it is very important to point out that this situation may be highly specific to OSR crops. Indeed, these crops are rich in pollen and nectar available during the winter and cropping disruptions (pesticides applications, harvest, ploughing or fertilizing) are rare during the winter period. As parasitoids often only need hosts, pollen, nectar and shelter to survive and as this crop fulfils all these needs, it is not surprising to find these results. It is important to keep in mind that the results might not be the same in winter wheat fields for example. 
Other studies have demonstrated that habitat configuration complexity increased parasitoid abundance and richness in rice systems (Dominik et al. 2018; Martin et al. 2016; Ulina et al. 2019). Abundance and richness was elevated by greater structural connectivity of

362

363

364

365

366

367

368

369

370

371

372

373

374

375

376

377

378

379

380

381

382

383

384

385

386

387

388

389

390

391

392

393

394

395 rice fields (Dominik et al. 2018) and the small-grain of rice landscapes with high connectivity between fields (Ulina et al. 2019) facilitating the spillover of the parasitoids (Martin et al. 2016). Conversely, greater habitat fragmentation reduced the presence of parasitoids in rice fields (Dominik et al. 2018). Interestingly, the parasitoids were more affected by landscape configuration complexity than by the presence of their hosts (Dominik et al. 2018) or by the amount of semi-natural habitats (Martin et al. 2016) suggesting that landscape configuration could be a crucial factor in preserving natural enemy efficiency in cropped lands. A conclusion is that the proximity of diversified resources seems more important than the diversity of resources alone (Martin et al. 2016).

Habitat configuration complexity may have no particular impact on hosts or parasitoids and parasitism rates (Hawro et al. 2015; Plećaš et al. 2014; With and Pavuk, 2019). This can be when the effects of habitat composition overcome habitat configuration complexity (With and Pavuk, 2019; but see Haan et al. 2020) or host availability overcomes the direct effect of habitat configuration on parasitoids and parasitism rates (Hawro et al. 2015). As noted above, the effects of habitat configuration on parasitism and biocontrol can markedly differ between geographic regions and years due to variation in population sizes, species pools or turnover (Hawro et al. 2015, Plećaš et al. 2014).

\subsection{Synthesis and perspectives}

The use of chemical pesticides has negative effects on the survival of parasitoids and on their reproductive capacity, whereas nitrogenous chemical inputs overall positively affect parasitoid populations through bottom-up improvements in host quantity and or quality. The use of biopesticides is one proposed solution to the impact of chemical pesticides on non-target organisms, but the results are mixed and it seems that similarly adverse effects on parasitoid populations are possible (Alves et al. 2019; Biondi et al. 2013). Consideration of the use of refuge zones around the pesticide treated areas may allow the reinvasion of these areas by natural enemies, but the precise scale and configuration of such refuges remains a research active area. Furthermore, the policy to reduce the use of agrochemicals is encouraging the development of new pest control methods and the use of biocontrol as an ecosystem service. The combined use of pesticides and parasitoids is not incompatible and can be considered in integrated pest management (IPM) programs if these interventions are carefully timed (Biondi et al. 2013; Desneux et al. 2007; Milonas et al. 2021; Rakes et al. 2021; Williams et al. 2003). However, this field of study sorely lacks practical, working examples. Most studies assessing bottom-up effects of external inputs on parasitoids are conducted under laboratory conditions 
396

397

398

399

400

401

402

403

404

405

406

407

408

409

410

411

412

413

414

415

416

417

418

419

420

421

422

423

424

425

426

427

428

429

430

431

432

and in the case of pesticide use, only the impact of sublethal effects on reproduction is mainly considered. To satisfactorily assess the impact of pesticides on parasitoids, additional field studies are needed (Pinheiro et al. 2020). In addition, very few studies have been conducted on hyperparasitoids despite their primary role in the success of biocontrol programs using parasitoids (Frago et al. 2012; Schooler et al. 2011; Vyas et al. 2020). Furthermore, it is expected that the bottom-up effects of $\mathrm{N}$ and pesticide use would be more important in organisms higher up the food chain through bioaccumulation, but this does not appear to be the case since the hyperparasitoid population was less impacted by pesticide use than the primary parasitoids (e.g., Longley et al. 1997). Further studies are needed to determine the precise effects on hyperparasitoids because if they are found to be less impacted than primary parasitoids, the pressure supported by bottom-up effects of land use intensification and topdown effects unbalancing primary parasitoid/secondary parasitoid populations may drastically modulate primary parasitoid populations and reduce the ecosystem services they provide.

Enhancing natural enemy abundance and biocontrol can be done by manipulating landscape configuration and composition, although they are often highly interconnected and hard to disentangle in their effects (Haan et al. 2020; Martin et al. 2019). Landscape composition complexity has contrasting effects on parasitoids and parasitism rates with positive (Elliott et al. 2018; Gagic et al. 2012; Grab et al. 2018; Plećaš et al. 2014), negative (Hawro et al. 2017; Zhao et al. 2015) and neutral (Gagic et al. 2012) responses reported. Such variability and inconsistency may arise from regional variation in species group identity (Thies et al. 2011) or food web structure acting on the parasitoid (Ulina et al. 2019). The positive effect of landscape configuration on parasitoids seems more consistent (but see Plećaš et al. 2014; Hawro et al. 2015; With and Pavuk, 2019). Moreover, recent studies have shown that effects of landscape composition variables can be secondary to effects of landscape configuration (Haan et al. 2020) showing the importance of the latter as a potential lever to increase biocontrol. Indeed, a growing number of studies have highlighted the impact of landscape configuration on parasitoids capacity to survive and parasitize in a given landscape (Martin et al. 2016; Berger et al. 2018; Ulina et al. 2019).

From these assessments, we can conclude that manipulating landscape configuration to increase parasitoid populations might be a viable option to activate natural biocontrol in future agricultural landscapes. Some key steps to activate natural biocontrol services from parasitoids may include: 1 . enhancing connectivity between the different food resources of parasitoid species or life-history stages to facilitate population persistence and spillover of parasitoids, 2. promote small field sizes to enable parasitoid spillover to reach the centre of fields, 3. increase the proximity between diversified resources in order to help parasitoids find complementary food resources (e.g., pollen and nectar, prey) and hosts. While reducing field sizes in highly intensified crop systems might be a good lever to improve parasitoid 
effectiveness, this might not necessarily be associated with increased cover of semi-natural habitats as they are not always efficacious in preserving parasitoids in a landscape (Berger et al. 2018). It might, however, be that increased crop diversity and use of complementary crop rotations or co-planting that divide current large monocultures into smaller, more diverse units (Shellhorn et al. 2011) can provide the spatio-temporal continuity of diversified food resource patches to enhance natural parasitism rates and reduce dependency on pesticide applications.

440

\section{2 - CLIMATE CHANGE}

442 Host-parasitoid systems can be disrupted when species respond differently to a climate 443 change (Jeffs and Lewis, 2013), although a species' biological adaptations and evolutionary 444 history shape responses to different aspects of climate change (e.g., Ewald et al. 2015; 445 Sinclair et al. 2016). In this section, we discuss the likely and observed effects of climate 446 change on parasitoids and on their interactions with their hosts, and identify some current 447 challenges for making predictions in this area (Figure 3). Evidence for effects on parasitoids 448 of climate change induced bottom-up effects often comes from semi-natural ecosystems (e.g., 449 forests), but we consider such findings here as they can still inform on potential impacts in 450 agricultural systems.

\section{[Insert Figure 3 here]}

Figure 3. Direct and indirect effects of climate change (temperature and water regime changes, increased atmospheric $\mathrm{CO}_{2}$ ) on ecological mechanisms producing positive and/or negative impacts on plant-host-parasitoid interactions (and their symbionts). Images sourced from thenounproject.com (CC-BY: Carpe Diem; Denimao; Megan Strickland; Phạm Thanh Lộc).

\subsection{Direct impacts of climate change on parasitoids}

Temperature is a key factor affecting parasitoid performance (Abarca and Spahn, 2021; Hance et al. 2007; Le Lann et al. 2021). It does so, however, in a non-linear way with gains in performance from a lower thermal limit up to an optimal temperature, followed by an abrupt decrease as the highly constrained upper thermal limit is approached (Furlong and Zalucki, 2017; Stoks et al. 2017). Parasitoid responses to global warming will therefore depend upon how current and future conditions align with their evolved thermal performance. Temperature performance may be trait-dependent, and that alone could alter host-parasitoid interactions under climate change (Foray et al. 2014). Under increased temperatures, parasitoids could develop faster, but at the expense of reduced body size and energetic resources (Foray et al. 2014; Moore et al. 2020; Schreven et al. 2017). A meta-analysis by Wu et al. (2016a) found differences in temperature response between Trichogramma parasitoid species, widely used 
as inundative biocontrol agents, related to the geographical source of the species and were therefore likely due to evolved thermal adaptations among species.

The consequence of temperature changes for any particular host-parasitoid interaction will depend on the combination of life-history impacts that result. Romo and Tylianakis (2013) found higher temperature reduced longevity of Diaeretiella rapae parasitoids, but increased emergence success, resulting in greater suppression of aphid pests Brevicoryne brassicae on Brassica oleracea. However, changes to individual life-history elements do not necessarily result in changes to overall parasitism outcomes. MorenoDelafuente et al. (2021) found a reduced development time of the parasitoid Aphidius colemani parasitizing its aphid host Rhopalosiphum padi under the combination of increased temperature and $\mathrm{CO}_{2}$ level, but parasitism rate was unaffected. Nevertheless, since the upper thermal limit is generally higher for the host than its associated parasitoid, increased temperatures should generally favour the host over its parasitoid (Agosta et al. 2018; Moore et al. 2021; Stoks et al. 2017). In addition, the tight constraints on upper thermal limits for insects leave limited adaptation potential, especially for species already under thermal stress (Hoffmann et al. 2013), and may lead to reduced parasitoid reproductive rates as limited lipid resources are allocated to body maintenance instead (Denis et al. 2013).

As climate change advances, parasitoid behaviour will also be impacted, often in nonlinear ways, by exposure to episodic extreme temperatures (e.g., heat waves). Such behavioural alterations are likely to affect host location and parasitism success, but the direction of the effect appears to vary between species and the behavioural traits measured. Valls et al. (2020) found that heat shock during foraging reduced parasitoid activity, resulting in a reduction in the number of aphids parasitized. In a different species combination, high temperature exposure has been shown to reduce search time and increase parasitism rate (Jiang et al. 2018). In the latter example, at higher temperature the parasitoid also appeared better able to discern unsuitable hosts that had been infected by a virus (Jiang et al. 2018). Flying and walking capacities may also be affected by changes in temperature; Jerbi-Elayed et al. (2015) found that flying and walking capacities of parasitoids were reduced and increased, respectively at higher temperatures in association with a reduction in reproductive potential. Overall different responses between species and traits hamper predictability and indicate that a detailed understanding of each host-parasitoid combination is necessary.

Warmer conditions due to global climate change may paradoxically increase parasitoids' exposure to cold temperature extremes (Abarca and Spahn, 2021). This is because warmer autumnal conditions may delay diapause induction, while warm winter conditions will shorten diapause (Bale and Hayward, 2010) leading to increased parasitoid mortality and reduced longevity and fecundity (reviewed in Hance et al. 2007). Mirroring the upper thermal limit, the lower thermal limit of parasitoid activity is probably higher than that of 
their host (Liu et al. 2016), and parasitoid species extending their activity window as a response to warmer temperatures may have a limited adaptation potential to cold extremes, as found in Aphidius avenae (Hymenoptera: Braconidae: Aphidiinae) (Alford et al. 2020). most likely to affect parasitoids indirectly through bottom-up effects on vegetation and hosts (section 2.2.). Research on the potential direct effects of elevated $\mathrm{CO}_{2}$ and increased atmospheric pollutants on parasitoids and parasitism is scarce in comparison to temperature, perhaps due to the more specialist experimental infrastructure required. Ozone pollution can negatively affect host searching behaviour of the Drosophila parasitoid Asobara tabida (Gate et al. 1995), but is unclear if this due to direct physiological impairment (e.g., of olfactory systems) - as demonstrated in insect pollinators (Vanderplanck et al. 2021) - or by host kairomone degradation by air pollutants (e.g., Himanen et al. 2009).

520

\subsection{Plant- and host-mediated impacts of climate change on parasitoids}

522

Because parasitoid fitness is tightly linked with host quality (Godfray 1994), climate change effects of increased temperature, elevated atmospheric $\mathrm{CO}_{2}\left(\mathrm{eCO}_{2}\right)$ and droughts may induce bottom-up (plant- and host-mediated) impacts on both parasitoid behavior and development (Thomson et al. 2010).

A fundamental mechanism underpinning plant-host-parasitoid tri-trophic interactions is the attraction of parasitoids via herbivore-induced plant volatiles (HIPVs) (Dicke and Baldwin, 2010; Du et al. 1998; Turlings et al. 1991). Climate-induced abiotic stressors are likely to affect HIPV emissions by plants, jeopardizing this chemical communication between plants and parasitoids (Becker et al. 2015; Harvey, 2015; Jamieson et al. 2017; Yuan et al. 2009). The effect of climate change on plant-parasitoid interactions via HIPVs is multifaceted with effects manifesting through changes in the volume, composition, perception by insects, or environmental persistence of HIPVs (Ode et al. 2006; Pinto et al. 2007). Increased eCO $\mathrm{CO}_{2}$ from 360 to $720 \mathrm{\mu l} \mathrm{I}^{-1}$ in Brassica oleracea caused a reduction in the emission of two HIPVs induced by the host Plutella xylostella, and the associated parasitoid Cotesia plutellae no longer responded to the plant signal (Vuorinen et al. 2004). Conversely, Himanen et al. (2009) found increased emissions of most terpenoids of Brassica napus under equivalent elevated $\mathrm{eCO}_{2}$ had no effect on attraction of Cotesia vestalis to $P$. xylostella host-infested plants.

Drought stress can also have negative, positive or negligible impact on HIPV emissions and parasitoid recruitment. Drought altered HPIVs of Citrus trees infested with Diaphorina citri preventing attraction of their parasitoid Tamarixia radiata (Martini and Stelinski, 2017).

542 Similarly, B. oleracea HIPV emissions induced by the aphid Myzus persicae were reduced 543 under drought, lowering parasitoid recruitment, particularly for the specialist species 544 Diaeretialla rapae (Tariq et al. 2013). In contrast, drought elicited no change in parasitoid 
attraction in the Brassica oleracea - Mamestra brassicae - Microplitis mediator system (Weldegergis et al. 2015), indicating how outcomes can differ according to species identity.

Disentangling plant- and host-mediated effects on parasitoid performance requires

548

549

550

551

552

553

554

555

556

557

558

559

560

561

562

563

564

565

566

567

568

569

570

571

572

573

574

575

576

577

578

579

580 complex experimentation and clear examples are therefore scarce. Effects discussed in this section may in fact be the result of plant-mediated effects on herbivores, that then have knockon consequences for their parasitoids. Temperature increases can have complex, multigenerational and multi-directional effects on host-parasitoid interactions. Iltis et al. (2020) experimentally separated the effects of warming on adults of the parasitoid Trichogramma cacoeciae and their parasitic offspring (eggs) in the host Lobesia botrana (Tortricidae). Warming of the parental generation reduced the pupal mass and the nutritional quality of their eggs, which resulted in a reduced emergence rate of the next generation. However, direct warming of the parasitized host (e.g., during parasitoid development) did not significantly affect the host-parasitoid interaction in that generation. One adaptation to high temperature by koinobiont parasitoids is their ability to manipulate the behaviour of their hosts to mummify in a more optimal temperature environment (Hance et al. 2007). Without which, host reaction to heat stress may protect them against parasitism, as seen with greater survival of Acyrthosiphon pisum aphids from parasitism by Aphidius ervi after exposure to a heat shock (Trotta et al. 2018).

Climate change may alter the chemistry of primary (N, P, C, amino acids) and secondary plant metabolites with a defensive function (Harvey, 2015; Ode et al. 2014). Under $\mathrm{eCO}_{2}$ plants capture more carbon relative to nitrogen resulting in a decrease in foliar nitrogen content impairing herbivores' performance and potentially their quality as hosts for parasitoids (Bezemer et al. 1998; Jeffs and Lewis, 2013; Thomson et al. 2010). It can also reduce plant quality and thereby increase host feeding, lengthen host development and alter host fecundity (Schulze-Sylvester and Reineke 2019; Stacey and Fellowes, 2002; Sun et al. 2011; Wang et al. 2014). Roth and Lindroth (1995) found that $\mathrm{eCO}_{2}$ both reduced foliar nitrogen content and increased foliar phenolic and starch content in aspen trees. This increased leaf consumption, slowed development, and reduced final weight of gypsy moth Lymantria dispar L. larvae, which led to greater mortality and slightly reduced female body size of the parasitoid Cotesia melanoscela. Reduced vegetation quality can also increase parasitism, however. Lower foliar nitrogen content increased leafminer mortality in a natural Quercus community, partly due to the plant effect, but mainly through increased parasitism (Stiling et al. 1999). The knock-on consequences for parasitoids of $\mathrm{eCO}_{2}$ effects on host quality may therefore be positive (Sun et al. 2011) or negative (Schulze-Sylvester and Reineke, 2019), while impacts on parasitism rates remain unresolved (Schulze-Sylvester and Reineke, 2019; Sun et al. 2011; Wang et al. 2014). 

herbivorous host performance and the performance of their parasitoids (Aslam et al. 2013; Johnson et al. 2011; Munir et al. 2016). Holton et al. (2003) found a decreased nitrogen content but increased tannin content in the quaking aspen Populus tremuloides under $\mathrm{eO}_{3}$, while $\mathrm{eCO}_{2}$ only caused decreased nitrogen content. Forest tent caterpillars Malacosoma disstria had an improved performance under $\mathrm{eO}_{3}$ at ambient $\mathrm{CO}_{2}$ levels, but a reduced performance under $\mathrm{eCO}_{2}$ and $\mathrm{O}_{3}$, while their parasitoids Compsilura concinnata (Diptera) had an increased mortality under $\mathrm{eO}_{3}$. Wade et al. (2017) found that continuous drought reduced the plant biomass of Hordeum vulgare L. while a drought/deluge regime (reduced rainfall events but not rainfall volume), did not. The drought/deluge regime also increased the nitrogen and amino acid foliar content, and increased by $15 \%$ the mass of aphids Sitobion avenae, Metapolophium dirhodum, and Rhopalosiphum padi and by $66 \%$ the mass of ladybirds Harmonia axyridis. However, the parasitism rate was not affected (Wade et al. 2017). Finally, drought stress may increase or decrease host quality. For example, slower development and reduced body size of $S$. avenae aphids on drought-stressed wheat reduced Aphidius parasitism rate (Ahmed et al. 2017; Nguyen et al. 2018). Ahmed et al. (2017) also showed that aphid species adapted to more humid conditions could no longer defend against parasitoids under drought which could improve parasitism success rate and biocontrol. Similarly, Kansman et al. (2021) found an improved suppression of $R$. padiaphids by Aphidius colemani under water limitation. While water stress increased aphid size and maximized parasitoid performance, parasitism rate was lowest under high-water stress, although this was accompanied by simultaneously poor aphid performance driving their abundance down

603 (Kansman et al. 2021). Conversely, Calatayud et al. (2002) found improved immune responses of mealybugs on water-stressed, water-resistant cassava plants, leading to a higher rate of encapsulation of their endoparasitoid.

Overall, climate change drivers may directly or indirectly reduce host nutritional quality which will reduce parasitoid fitness (Facey et al. 2014) or reduced host immunity to parasitism which may lead to the opposite. The impact of these different climate change drivers tend to have a negative impact on parasitoid behavior and performance even if the response seems species-specific. Combinations of these climatic factors are likely to result in

611 different outcomes compared to their individual effects (Romo and Tylianakis, 2013). However, 612 there is little research to date on plant-and host-mediated impacts of combined climatic factors or extreme climatic events on parasitoids performance or adaptation potential.

614

\subsection{Endosymbiont-mediated impacts of climate change on parasitoids}

616 Host-parasitoid interactions can be influenced strongly by the presence of endosymbiotic 617 bacteria, with several bacterial species able to increase host resistance to parasitism (Oliver 
et al. 2014). Changes in temperature could profoundly affect endosymbionts, with implications

619 for host-parasitoid interactions (Corbin et al. 2017). The protection provided by the aphid 620 symbiont Hamiltonella defensa is temperature-dependent (Bensadia et al. 2006), probably 621 due to heat damage to the bacterium. Consequently, we might expect diminished 622 endosymbiont protection against parasitoids in heat-sensitive bacteria faced with increased 623 frequency of episodic heat waves or sustained higher temperatures. Other symbiont species 624 are able to withstand heat damage, and may thus offer redundancy in symbiont-mediated 625 protection from parasitism (Guay et al. 2009; Heyworth et al. 2020). Symbionts shown to 626 protect aphids from heat stress can also exacerbate host vulnerability to parasitoids e.g., aphid 627 harboring X-type symbionts are more susceptible to parasitism than cured aphids (Heyworth 628 and Ferrari, 2016). One symbiont that can at least occasionally increase aphid resistance to 629 parasitism (Serratia symbiotica; Oliver et al. 2003) is found more frequently in hot 630 environments (Henry et al. 2013), possibly due to an ability also to protect the insect host 631 against heat stress (Montllor et al. 2002). In environments where heat stress becomes more 632 common, we might anticipate parasitoid resistance, because of the selection pressure due to 633 rising frequencies of $S$. symbiotica.

635 complex. Host feeding on drought-stressed plants may influence symbiont-infected and 636 symbiont-free aphids differently, and speculative modelling work indicates this could disrupt 637 co-existence of symbiont-free and symbiont-infected aphids, with knock-on effects on 638 parasitism (Preedy et al. 2020). Impacts of climate change (including temperature and $\mathrm{eCO}_{2}$ ) 639 on emission of plant volatiles (see above) could interact with known effects of herbivore 640 symbionts on plant volatiles (Frago et al. 2017), but experimental evidence of the direction 641 and magnitude of such interactions is currently lacking.

642 Symbionts are, however, not limited to herbivorous hosts; many parasitoids also carry 643 symbiotic bacteria. In several species of Trichogramma, Wolbachia endosymbiont presence 644 is correlated with heat tolerance (Pintureau and Bolland, 2001; Wu et al. 2016b). Considering 645 the symbiont status of parasitoid genotypes is therefore one aspect of predicting biocontrol 646 potential under climate warming or extreme heatwave event scenarios. Alternatively, changing 647 climate could result in significant changes to symbiont frequencies and/or identities in both 648 insect herbivores and their parasitoids, but if the consequence of symbiont turnover is to 649 maintain insect phenotypes, this would result in very little visible change in the external insect communities.

\subsection{Community structure and species interactions}

653 Climate change may affect both species assembly within communities and interactions within 654 food webs (Thierry et al. 2019). Tougeron et al. (2018) identified a recent species 
diversification over nine years in a temperate winter cereal aphid-parasitoid-hyperparasitoid community, that was partially explained by increased minimum temperatures and the reduced frequency of frost events. Salazar-Mendoza et al. (2021) similarly found that the species richness of fruit flies and their associated parasitoids and parasitism rate were higher at lower elevations. Under climate change, such displacement of the favourable 'climate envelope' hosting a high diversity and abundance of parasitoids towards higher latitudes could leave lower latitudes depleted due to harsher temperatures.

The community-level parasitism rate may also be affected by the precipitation regime. Over a large spatial scale, parasitism rate correlates negatively with increased variability of precipitation (Stireman et al. 2005), which is predicted to be drastically exacerbated by climate change (Pendergrass et al. 2017). Similarly, Salcido et al. (2020) found that weather anomalies leading to flooding events were likely at least partially responsible for the strong decline in species richness of caterpillars and parasitoids, interaction richness and overall parasitism rate in a tropical Costa Rican community over a 22-year survey. Changes in temperature regimes may alter species relative abundances and interaction strengths. Under simulated heatwave conditions, Gillespie et al. (2012) found a reduced total parasitism rate but an increased competition for hosts between Aphidius matricariae and Aphelinus abdominalis parasitizing Myzus persicae aphids. Enhanced competition under heatwaves was also found between hyperparasitoids (Chen et al. 2019). Conversely, competition was unchanged in a Drosophila (host) - Asobara (parasitoid) community under increased temperatures, and reduced parasitism rate was instead a direct consequence of reduced parasitoid performances (Thierry et al. 2021). Finally, Bonsignore et al. (2020) found that short-term cold stress affected the relative frequencies of parasitoids emerging from Asian cynipid gall wasps in chestnut trees. Range expansions due to climate change provide an additional source of changes in community structure and interactions. For example, Audusseau et al. (2021) found that range expansion of one nettle-feeding butterfly (Araschnia levana) was associated with an increased parasitism rate in existing resident nettle-feeding butterfly species.

The impacts of other aspects of climate change on species interactions, notably drought, remain understudied. However, temperature and rainfall will, of course, act in combination. Derocles et al. (2018) found that increased temperatures and rainfall synergistically exacerbated asymmetry of interactions in a wheat-aphid-parasitoid community, with aphid abundances doubled but with overall similar parasitism rate. This could lead to outbreaks of the main pest species, but perhaps also secondary outbreaks of minor pest species due to the enhanced interaction asymmetry relaxing top-down control. In a $42-$ year survey in cereal fields, Ewald et al. (2015) found that braconid abundances increased in hot/dry years and decreased in cold/wet years, but aphid or chalcid wasp abundances were 
less strongly correlated to extreme events, suggesting the dominant parasitoid groups in a community may shift if average weather patterns change. However, climate change may not always have a major impact on more functionally diverse communities with multiple natural enemies: combined $\mathrm{eCO}_{2}$, higher temperature and decreased precipitation reduced survival of nematodes, but not parasitoid wasp, ladybird or spider survival (van Doan et al. 2021).

\subsection{Impacts of climate change on phenology}

Changes in climate are already driving changes in insect phenologies (Abarca and Spahn, 2021; Forrest, 2016). These changes can arise from direct physiological effects of warmer climates such as speed of development, knock-on effects of changing plant phenologies (e.g., timing of leaf burst), and changes to previously reliable signals for developmental timing (e.g., for entering or exiting diapause). All these alterations could have consequences for hostparasitoid interactions, especially if they result in a mismatch between host and parasitoid phenologies.

A straightforward physiological effect of climate change is that higher temperatures can result in a faster life cycle. For instance, increased temperatures reduce development time in Spodoptera exigua, allowing a temporal escape from its parasitoid Cotesia marginiventris and hence a dramatic reduction of pest control (Dyer et al. 2013). This is also the case where higher temperatures reduced the temporal occurrence of cynipid chestnut gall wasp (Dryocosmus kuriphilus, Hymenoptera: Cynipidae) and increased asynchrony with parasitoids (Bonsignore et al. 2019). Similarly, increased temperatures from 20 to $35^{\circ} \mathrm{C}$ reduced the period of susceptibility of the emerald ash borer Agrilus planipennis to parasitoid attacks (Duan et al. 2014).

Climate change may also affect host-parasitoid phenology through bottom-up plant mediated effects. Warmer spring temperatures may cause plant phenology to be shifted earlier disrupting the higher trophic levels. This was the case in a fern-moth-parasitoid system, where the host and parasitoid were slower at tracking this phenological shift, resulting in an increased asynchrony between the trophic levels (Morse, 2021). In the sycamore, Acer pseudoplatanus, warmer spring temperatures caused earlier budburst but delayed the emergence of aphids while parasitoid attacks were advanced (Senior et al. 2020). An increase in $1.9^{\circ} \mathrm{C}$ has also caused a phenological shift in wheat growth, increasing the abundance and reproduction period of aphids Sitobion avenae, but left parasitoid abundance unaffected and lowered the parasitism rate (Han et al. 2019).

Diapause is generally induced and ended by environmental cues, such as day length or temperature at higher latitudes and rainfall in tropical regions (Bale and Hayward, 2010). Warmer winters in temperate regions may cause diapause termination, and the differences in lower thermal limits between hosts and parasitoids may cause asynchrony in their respective 
development (Hance et al. 2007). In the passion vine hopper Scolypopa australis Walker (Homoptera: Ricaniidae), abnormally warm summer temperatures disrupted the diapauseinduced synchrony between the pest and its normally univoltine egg parasitoid Centrodora scolypopae Valentine (Hymenoptera: Aphelinidae), and this caused the parasitoid to have a second unsuccessful generation (Gerard 2004). Over the long term, this could cause a drastic reduction in the abundances of parasitoids.

Where insect herbivores and their parasitoids exhibit a different phenological response to climate change a mismatch can occur, to the benefit or detriment of either party. In general, greater mismatch will favour the herbivore while greater synchrony will benefit the parasitoid. Asynchrony is most likely where parasitoids and their hosts use different phenological cues (or respond differently to the same cue). Insect life-history is an important element of whether or not synchrony is likely to be affected. For example, if parasitoid diapause depends entirely on the host, synchrony will be maintained, whereas asynchrony can develop if spring emergence of host and parasitoid is controlled by different cues and becomes decoupled (Damien and Tougeron, 2019).

Asynchrony between hosts and parasitoids has been found under experimental warming in natural forest caterpillar-wasp communities: both caterpillars and hosts emerged earlier, but the effect was stronger for caterpillars leading to partial decoupling (Abarca and Lill, 2019). In a 10-year survey of cereal leaf beetles in Utah, warm spring temperatures advanced the population growth of beetles but not of parasitoid wasps, causing enhanced asynchrony and reduced parasitism (Evans et al. 2013). In other systems, warmer spring temperatures may instead increase host-parasitoid synchrony: the host butterfly Melitaea cinxia and its parasitoid Cotesia melitaearum show some asynchrony under normal temperatures. This is notably due to the different colours of the caterpillars (dark) and the parasitoid cocoons (pale) as dark-coloured caterpillars basking in the sun increase their body temperature. In addition, the ability of caterpillars to move to seek a warmer microclimate and thus develop more quickly - under warmer temperatures parasitoid phenology is advanced, reducing asynchrony (Van Nouhuys and Lei, 2004).

Outcomes from experimental studies range from dramatic reductions in parasitism rate (e.g., Dyer et al. 2013) to no major change in parasitism (Bale and Hayward, 2010). However, by incorporating understanding of insect life histories, including the cues that are used to align development with food-plants (in the case of herbivores) or insect hosts (in the case of parasitoids), experimental laboratory studies and field observations, it may become possible to predict the likely impacts of climate change on phenology for a range of specific systems (Forrest 2016). 


\subsection{Impacts of climate change on species distributions} Insects may respond to changing climate, altering their geographic distribution. As temperatures change, range expansions and contractions will be observed, according to the thermal limits of the insects involved and the speed with which they are able to track the changing environment. Just as with phenological responses to climate change, geographic shifts may be different for herbivores and their natural enemies, altering the rates of parasitism. Crop distributions will also be change with new climate and herbivorous pests might be able to track such changes faster than their natural enemies, especially parasitoids which have a reduced dispersal capacity relative to their hosts' (Thomson et al. 2010).

Such decoupled range shifts and the release of parasitism pressure has been observed in natural communities: Menéndez et al. (2008) observed a northward expansion of the brown argus butterfly Aricia agestis in Great Britain, with a reduced parasitism rate in the newly colonized areas. Similarly, parasitism pressure by parasitoid wasps was released at the expanding margin of fig wasps' geographic distribution (Mackay et al. 2020). In an Arctic community, a community shift over 22-years from parasitoids of Lepidoptera to parasitoids of pollinator Diptera related to increased summer temperatures caused greater lepidopteran herbivory but reduced dipteran pollination (Kankaanpää et al. 2020).

Parasitic interactions are predicted to be the most sensitive to climate-induced species range shifts: parasitoids were less able to track climate change and host range shifts, compared to mutualist or commensal species (Singer et al. 2013). Modelling approaches applied to crop pest-natural enemy communities predict changes in the distribution of crop damage under climate change. In Australia, Furlong and Zalucki (2017) predicted a decoupling between regions suitable for the lepidopteran pest Plutella xylostella and its parasitoid Diadegma semiclausum that would shrink the parasitoids northern range, whilst allowing continued crop damage by the pest. Conversely, the light brown apple moth Epiphyas postvittana is sensitive to warm temperatures and is predicted to shift towards temperate southern Australia, where it could increase crop damage unless generalist parasitoids with a large geographic distribution are able to control it (reviewed in Thomson et al. 2010). Climateinduced range shifts may potentially result in improved pest control in high latitude regions where biocontrol has failed historically: Peristenus digoneutis (Hymenoptera: Braconidae) is predicted to expand northwards throughout Canada and northern Europe, where it could improve the control of Lygus bugs (Olfert et al. 2016). Similarly, the distribution of Trichogramma ostriniae is predicted to expand in northeastern China and North America with climate change, potentially biocontrol of its host Ostrinia nubilalis.

Potential host-parasitoid spatial decoupling and the success of introduced parasitoid biocontrol agents will depend on the life history of both the parasitoids and the host. For instance, warmer temperatures in the southern part of their range have been shown to cause 
emerald ash borer Agrilus planipennis to overwinter deeper in the wood of their host plant, where they are no longer accessible to their parasitoid Tetrastichus planipennisi (Gould et al. 2020). Under climate change, therefore, the suitable geographic area for the establishment of the parasitoid introduced as a biocontrol agent is predicted to shrink dramatically at the southern margin of their range. At the northern extent, the increased frequency of extreme cold events induced by climate change may also compromise ash borer control due to parasitoid mortality (Duan et al. 2020).

810

\section{2.7. Synthesis and perspectives}

812 To conclude, the potential of climate change to impact parasitoids, and especially host813 parasitoid interactions, has been widely studied in laboratory and field systems, in both 814 manipulation and observational studies. It is clear that climate change has the potential to 815 disrupt host-parasitoid interactions, but with variable outcomes for the rate of parasitism. 816 Indeed, herbivores would benefit from these changes by avoiding parasitism. Hosts may have 817 a reduced development time shortening the risk of exposure to parasitoids. The upper thermal 818 limit of the host is generally higher than its parasitoid and a greater phenological mismatch 819 may favour the herbivore, particulary as herbivores tend to track their host plants faster than parasitoids. Herbivores that are favoured by climate change through bottom-up effects could cause major pest outbreaks and important crop damage as they overwhelm the potential biocontrol that parasitoids provide. However, precise outcomes depend on individual species' characteristics, and these drive differences in relative importance of the multiple aspects of parasitoid and host life-history that combine to determine parasitism rates. In addition, few studies incorporate the multiple components of predicted climate change simultaneously. It is important to recognise that insect responses to climate change are not fixed - we would expect to see both plastic and evolutionary adaptation, even if the evolutionary response cannot keep pace with the rate of climate change. The laboratory experimental work we review in this manuscript does not take into account potential plastic transgenerational responses to changing conditions that might mitigate some impacts in subsequent generations. Likewise, in observational field studies where parasitoids are expanding their range more slowly than their hosts, this may be only a temporary lag that will be overcome in future years (Stone et al. 2012), provided that the parasitoid can persist within its original range in the meantime. In addition, effects of climate change such as altering distributions or phenologies of herbivores could provide opportunities for new host-parasitoid interactions. Host shifts, especially by generalist parasitoids, might thus permit biocontrol of herbivores to continue, even if the species assemblage changes. Invasion events show the potential for such shifts: for example, native parasitoids beginning to attack invasive Cameraria ohridella leaf miners in the UK (Pocock and Evans, 2014). Human introductions (biocontrol agents) are likely to be particularly 
840 vulnerable to climate change. New introductions of biocontrol agents should therefore take 841 into account efficacy not only in the current environment, but in projected future thermal

842 scenarios. Rather than predicting general patterns or even specific instances of changes to

843 parasitism in a changing climate, it may be more important for biocontrol to focus on

844 understanding what makes a particular system more robust to perturbations such as those

845 predicted to result from climate change. In particular, diverse or highly connected ecosystems

846 are more ecologically resilient than simplified ecosystems, i.e., they are better able to resist

847 and recover from disturbances and could provide a sustainable solution to limit the impact of 848 climate change (Feit et al. 2021; see 1.2 and 4.1).

849

850

\section{3 - BIOLOGICAL INVASION}

851 Invasions by non-native or alien species (IAS) often extirpate species and profoundly modify 852 native populations and community structure (David et al. 2017; Mack et al. 2000; Ragsdale et al. 2011; Vanbergen et al. 2018) (Figure 4). Intact, diverse or highly connected species networks may limit the probability of successful invasions because high diversity of species and phenotypic or functional traits may saturate the niche space available to the invading organism (David et al. 2017; Smith-Ramesh et al. 2017). Ecosystems with unoccupied niches space due to simpler, homogenous communities are thus more vulnerable to invasion. For example, the most concerned ecosystems include where the ecosystem was evolutionary isolated (islands) or where it has been highly modified by anthropogenic disturbance (David et al. 2017; Dawson et al. 2017; Frost et al. 2019; Vanbergen et al. 2018). Moreover, successful establishment of alien invasive species in a novel ecosystem is predicated on an adaptive advantage arising from a lack of coevolution between the native and alien species, where the latter prevails due to an advantage in competitive or trophic interactions (David et al. 2017; Díaz et al. 2019). Empirical data and simulation modelling suggest that species with larger body sizes and dietary generalists are generally more successful invaders across different trophic levels (Frost et al. 2019; Lurgi et al. 2014).

\section{[Insert Figure 4 here]}

Figure 4. The pathways and mechanisms by which the introduction of an Invasive Alien Species (IAS) can directly and indirectly affect community interactions and structure producing positive and negative effects on plant-host-parasitoid interactions. Black arrows represent interactions between native organisms in the absence of IAS, while green arrows represent potential interactions created by the introduction of IAS (plant, pest or parasitoid). Potential pathways to invader modification of native host-parasitoid systems include: (a) Invader occupies a vacant ecological niche; (b) Increased complementarity of parasitoid/pest actions; (c) Classical biocontrol program to introduce an agent to (re)establish top-down control of a pest; (d) Native herbivore/parasitoid able to control invading plant/pest; (e) 'Central-to-Reap, Edge-to-Elude' trait strategy enabling invasion. Images sourced from thenounproject.com (CC-BY: Baboon designs; Carpe Diem; Megan Strickland; Phạm Thanh Lộc). 

invasion of networks. One such analysis of invader fitness in different community contexts

883 (e.g., mutualistic, antagonistic, food webs) predicted key adaptive mechanisms in a 'central884 to-reap, edge-to-elude' trait strategy (Hui et al. 2021). This meant that the invader should 885 possess traits that position it to take advantage of positive (facilitator organisms, optimal resources) while avoiding negative (predation, competition) interactions in the novel environment. In the case of host-parasitoid communities, for a novel herbivore species to successfully invade and avoid parasitism, its traits should minimally overlap with the trait space of its optimal native consumer to reduce consumption rates by resident parasitoids. Whereas, to maximize consumption rates, the traits of an invading parasitoid should overlap with the central position of its optimal resource (native host) in the trait space of the resident resource community (Hui et al. 2021). This balance and alignment of traits (e.g., trophic niche partitioning) in the parasitoid community has implications for top-down regulation, for instance complementarity among parasitoid species in host resource use reduces competition that can lead to greater levels of community parasitism rates (Peralta et al. 2014; Wang et al. 2021).

This importance of trait space is central to the 'enemy release' hypothesis, which postulates that if a host or prey species (host plant, insect herbivore host) species is translocated beyond its natural range it is able to occupy and thrive in the novel enemy-free space lacking coevolved antagonists. Invasion of North American forests by the gypsy moth (Lymantria dispar L.; Lepidoptera) provides an illustration of this phenomenon with very low post-invasion parasitism rates and little sharing of parasitoids with native lepidopteran hosts (Timms et al. 2012). Ecosystem transformation by land conversion can create enemy-free space, such as with the invasion of Solanum myriacanthum plants into pastures cleared of tropical forest where a native butterfly (Mechanitis menapis) experienced a lack of parasitism compared to the native host plant (S. acerifolium) (Despland and Santacruz, 2020).

There is, however, variation in the degree that native parasitoid species are unable to adapt to the novel host insect (e.g., see Desneux et al. 2010, Ragsdale et al. 2011; Asplen et al. 2015). For instance, invasion of Europe and North America by the Asian fruit fly pest Drosophila suzukii showed how the composition of the native parasitoid community might limit the impact of the invading herbivore (Chabert et al. 2012). Parasitoid host range was important

911 with specialist parasitoid species unable to switch to the novel fruit fly host, perhaps due to a 912 lack of pre-adaptations to cope with the immunocompetence of the novel host or a lack of 913 appropriate cues stimulating parasitoid attack. In contrast, generalist parasitoids with a 914 naturally broad host range were able to include this invader in their diet (Chabert et al. 2012). 915 Therefore, contrary to the enemy release hypothesis, certain native parasitoids may be able 916 to adopt novel hosts to the extent they may regulate the invading herbivore population, as 917 shown by the capacity of Encarsia noyesi (Hymenoptera: Aphelinidae) parasitizing the 
918 invasive whitefly, Aleurodicus rugioperculatus (Hemiptera: Aleyrodidae) (Boughton et al. 919 2015) and of Necremnus tutae (Hymenoptera, Eulophidae) parasitizing the invasive moth Tuta 920 absoluta (Lepidoptera: Gelechiidae) (Biondi et al. 2018). Indeed, enemy-free space may only 921 facilitate the initial phase of novel pest species establishment and outbreaks because the 922 invasion process is spatially and temporally dynamic. As the pest moves across the novel 923 landscape, it may encounter new competent enemies able to attack it (geographic spread924 hypothesis) or parasitoids may adapt over time to the novel host and include it in their host 925 range (adjustment-hypothesis) (Grabenweger et al. 2010). Compared with native hosts, 926 invasive herbivores may, however, be suboptimal hosts that lower the reproductive success 927 of native parasitoids, this raises the potential risk that the parasitoid populations are so 928 disrupted by the invader that overall biocontrol pressure is relaxed in the longer term and 929 secondary outbreaks of native pests re-emerge (Abram et al. 2014). Conversely, native 930 herbivores may be suboptimal hosts for invasive parasitoids, reducing their ability to control 931 populations of exotic herbivores from the same geographic area (i.e., apparent competition; 932 e.g., Monticelli et al. 2021).

933 Indirect trophic interactions such as apparent competition may also drive patterns in 934 parasitism rates and host abundance across community or habitat networks (Chailleux et al. 935 2014) and differences in abundance across host species could lead to one-way indirect 936 interactions with strong structuring effects on host-parasitoid communities (Muller et al. 1999; 937 Valladares et al. 2001). One experimental study of host-parasitoid networks across the 938 interface of plantation and natural forest revealed how host sharing among parasitoids 939 determined attack rates and host population changes (Frost et al. 2016). Moreover, host940 parasitoid food webs in areas of natural and production habitats functioned as a landscape941 scale metaweb of host-parasitoid interactions (Frost et al. 2016). Still, herbivores with 942 overlapping parasitoid communities could exhibit independent population dynamics, or even 943 positive indirect interactions such as apparent mutualism (Tack et al. 2011). These findings 944 necessitate consideration of the whole landscape matrix of crop and non-crop habitats in order 945 to plan landscapes in ways that manage biocontrol services and restrict species invasions and 946 pest outbreaks.

947 Alien invasive plants are common invaders worldwide and can exert a profound 948 influence on the community of host-parasitoid interactions. The invasion of UK heathlands by 949 an alien plant Gaultheria shallon, a densely growing, perennial shrub native to North America, 950 modified the abundance of native herbivores and parasitoids and lowered parasitoid species 951 richness. Its impact on the higher trophic levels varied with the degree of specialism, however, 952 strongly reducing specialist abundance while leaving generalist unaffected. This invasion953 induced decline of specialists disrupted top-down regulation releasing generalist species from 954 competition via shared natural enemies (Carvalheiro et al. 2010). In another case, invasion of 
Portuguese forests by Acacia longifolia simplified the plant communities in ways that led to declines in the biomass, abundance and species and interaction richness of galling insect herbivores, their parasitoids, and inquilines. (Lopez-Nunez et al. 2017). Such dramatic shifts in communities raise the spectre of disrupted top-down regulation of herbivores and the potential for novel outbreaks or population dynamics.

The effects of invasive plants on parasitism and biocontrol in the highly anthropogenic agricultural landscape remain to be seen (Carvalheiro et al. 2010; David et al. 2017). It is possible that in such highly simplified ecosystems with low species diversity that invasion risks are high and, in combination with other pressures like climate change, may facilitate profound shifts in the community structure and function of host-parasitoid systems. Pantel et al. (2017) suggests that, in agroecosystems, invasive species follow the same dynamics as when pests that have been previously excluded by pesticide application or host suppression are reinserted. The role of network structure in facilitating or limiting invasion successes remains debatable. Insights from theoretical simulation models indicate that simpler, less connected food webs might be more resistant to invasions (Lurgi et al. 2014). In contrast, a global synthesis revealed that across all functional groups, invasion success was retarded by highly connected food webs (Smith-Ramesh et al. 2017).

As already mentioned (section 1 and 2), parasitoids use chemical cues from herbivoreinduced plant volatiles (HIPV) to locate and attack potential hosts (Becker et al. 2015). Alien species invasions have the potential to modify emissions of these kairomones in ways that disrupt functioning of native host-parasitoid interactions. Plant responses in terms of HIPV emissions are the product of evolution and so the impact of an invader will likely depend on the phylogenetic relatedness between the invading and native species (Desurmont et al. 2014). A recent laboratory study of HIPV emissions from Vicia faba, showed the volatile emissions induced by an invasive pentatomid bug (Halyomorpha halys) did not attract a native parasitoid and moreover when the invasive was co-feeding with a native pentatomid host (Nezara viridula) the parasitoid no longer successfully parasitized the native host (Martorana et al. 2017). This indicates the potential for invasive herbivores to disrupt established semiochemical signals, parasitoid behaviour and ultimately interaction webs.

984

\section{4 - INTERACTIONS BETWEEN DRIVERS AND PERSPECTIVES}

986

The published studies of global change deal in isolation with the three drivers reviewed in the foregoing sections. Yet these drivers are interlinked via multiple ecological and anthropogenic processes. For example, increasing temperature can facilitate the successful establishment of invasive species; and land use intensification and the expansion of monocultures lead to an increased use of chemical inputs (fertilizers and pesticides). These drivers can then operate 
al. 2008) on the behaviour and developmental capacity of herbivores, and on parasitoids, modulating their role as biocontrol agents. In this section we aim to consider the important forms of interaction among global change drivers and provide relevant examples.

Overall, interactions among drivers seem to have mainly synergistic effects on biodiversity (Sala et al. 2000) although a more recent meta-analysis found that only 20 of 57 experiments analysed identified synergistic interactions, with the remainder being nonsynergistic effects (24 antagonistic and 13 additive) on biodiversity (Darling and Côté, 2008). Simple and predictable additive effects were rare, suggesting more complex interaction outcomes are commonplace (Darling and Côté, 2008). In our review, general trends indicate that some global change drivers will enhance the development of many herbivore species, including fertilisation and landscape simplification, though $\mathrm{eCO}_{2}$ and pesticide use could have the opposite effect. By contrast, effects of these global change drivers on parasitoids - the third trophic level - are more difficult to predict, being highly variable and species-dependent. These interactive effects remain largely untested (Moon and Stiling 2000; Johns and Hughes 2002) and therefore represent a challenge in understanding how further global change will impact the delivery of ecosystem services.

1008

\subsection{Climate change interacting with land use change intensification}

While global change drivers frequently interact, several existing studies have demonstrated that climate is the dominant driver of change for parasitism. Parasitoid abundance (Johnson et al. 2011) or species richness (Corcos et al. 2018) increased with temperature and decreased under drought, but were not modulated in either study by habitat diversity even

1014 though a higher diversity of floral resources is known to support higher density and diversity of parasitoids (Tews et al. 2004). Parasitoid distribution and species richness are highly dependent on the distributions of their hosts, and this may be more strongly impacted by temperature than by habitat diversity (Corcos et al. 2018; Johnson et al. 2011); suggesting that changes in climate may override in some cases the positive effect of habitat diversification on parasitoid communities. Lakeman-Fraser and Ewers (2014) have shown that there were positive effects between habitat fragmentation and latitude (as a surrogate for temperature) on both the herbivores and parasitoid density but negative effects on the herbivory and attack rate. These results suggest that the effects of global changes on parasitoids are primarily the result of bottom-up processes. Synergistic effects of warming temperature and nitrogen input have also been shown to promote both herbivores and parasitoids densities by increasing host availability and size (i.e., quality) promoting parasitoid oviposition and development (De Sassi et al. 2012). By contrast, only the negative impact of the most severe level of drought stress in interaction with fertiliser cascaded up to parasitoid level (Shehzad et al. 2020), suggesting that only major impacts of global change on hosts may transmit to their parasitoids. 
1029 Ewald et al. 2015 demonstrated that braconid parasitoid abundances in cereal fields 1030 responded positively to hot/dry years and negatively to cold/wet years, but pesticide was the most important factor explaining the population trend. This suggests that a decrease in the use of pesticides could reduce the impact of climate change on the parasitoid population density. The effects of crop fertilizer use on herbivore and parasitoid populations may also modify the impact of the increased atmospheric concentration of $\mathrm{CO}_{2}$ causing climate change on trophic interactions. For example, increased atmospheric $\mathrm{CO}_{2}$ is associated with lower concentrations of nitrogen and other minerals in crop plants (Myers et al. 2014); greater use of fertilizer inputs may reduce these impacts of increased $\mathrm{CO}_{2}$ on plant quality (Chen et al. 2010).

Together with the multitude of direct and indirect interactions that may occur at species and community levels, and effect scales ranging from microhabitat to inter-continental, predicting the overall effects of global change on parasitoids is a complex problem. Farmer decision-making adds another layer of uncertainty in understanding how global change drivers will impact biocontrol in future landscapes. For example, farmers could modify crop varieties or species, fertilizer inputs, and irrigation use, to compensate for yield losses or adapt to changes in climate (Challinor et al. 2014). These crop management responses could have a range of important positive or negative impacts on parasitism including changes in crop attractiveness or resistance to herbivores, and changes in habitat availability at the field or landscape level. There are opportunities for synergisms, where broader climate change adaptation actions enhance biocontrol services. Farmers may seek to diversify agricultural production and engage in agri-ecological practices to stabilise their yields and incomes (e.g., Harkness et al. 2021). Crop diversification to spread risk of yield impacts and commodity price fluctuations due to climate change is one way for farm management to become more resilient (Degani et al. 2019, Haile et al. 2017, Harkness et al. 2021). These additional crops could also increase the potential for parasitoid populations to survive and find complementary food and shelter resources, whilst providing other ecosystem services such as soil erosion prevention, soil biota preservation, pollination services and micro-climate stabilisation (Degani et al. 2019). These changes in agricultural practices are therefore aimed at increasing the resistance and resilience of agroecosystems to climate change and land use intensification. They will need to be applied as soon as possible as we already see strong effects of climate change on agricultural production (Haile et al. 2017). Global agricultural policies will need to be put in place in order to help farmers switch from one system to another. New research will need to be done and new knowledge acquired. This long-term process is therefore urgent to implement if we want the agricultural system to be as resilient as possible. 
1066

1067

1068

1069

1070

1071

1072

1073

1074

1075

1076

1077

1078

1079

1080

1081

1082

1083

1084

1085

1086

1087

1088

1089

1090

1091

1092

1093

1094

1095

1096

1097

1098

1099

1100

1101

1102

\subsection{Biological invasion facilitated by both climate change and land use intensification}

Global warming may also lead to an increase in biological invasions as an increase in temperature can favour the establishment success rate of invasive species immigrating from countries with higher temperature. For example, in continental China, a $1^{\circ} \mathrm{C}$ increase in temperature has been associated with a 0.5 species/year increase in the establishment rate of invasive alien insects (Huang et al. 2011). The invasion of exotic species relative to global warming results in the geographic expansion of the niche of several species from different trophic levels migrating simultaneously or in a rapid succession. Such rapid community changes could affect local communities. In particular, a laboratory experiment demonstrated that the simultaneous arrival of a new herbivore and its parasitoid had a negative effect on the survival and parasitism rate of native organisms (Carrasco et al. 2017). Simple and lowdiversified species networks found in simplified cultivated landscapes may also facilitate the successful invasions of introduced organisms due to the large cultivated areas availability and the novel enemy-free space lacking coevolved antagonists (David et al. 2017; Smith-Ramesh et al. 2017; Despland and Santacruz, 2020). In addition, use of crop fertilizer increased plant quality, again facilitating the successful establishment of invasive species in a new environment (Han et al. 2014). Overall, effects of land-use intensification and climate change have the potential to elevate the risk of invasions by alien organisms that can modify native host-parasitoid interactions.

\subsection{Is specificity of organisms the key?}

Parasitoids are specialists in that they generally attack hosts belonging to the same family of insect hosts, unlike predators that tend to behave in more generalised way to consume more various prey with the principal limit on predation being body size. For this reason, parasitoids are preferred over predators in biocontrol programs because thelikelihood of non-target impacts is reduced and control efficacy on target pest populations is high (Heimpel and Mills, 2017). However, the host specificity of parasitoids still varies between extreme specialists that are only able to develop in a single host species compared to more generalist parasitoids that are able to attack hosts belonging to different tribes or even a few families (Godfray 1994). Parasitoid specialization can also occur at the plant level where some are able to specialize on all potential hosts feeding on a specific host plant (Monticelli et al. 2021).

Our review, demonstrate that the impact of interacting and non-interacting global change drivers on parasitoids depends mainly on the effects on their hosts. This is mostly due to the strong dependence of a parasitoid on its host as the entire nutritional and physiological environment of the immature stage (Godfray 1994). Understanding the effect of global changes on parasitoids therefore requires a good understanding of the effects on herbivores which both appear to depend on the degree of ecological specialisation (Rand and Tscharntke, 
2007; Tylianakis et al. 2008) (Figure 5). Specialist herbivores, by definition, have coevolved with their hosts enabling them to have a high fitness through optimal use of resources and circumventing host defenses (e.g., Carolan et al. 2009; Wittstock et al. 2004; Zust and Agrawal, 2016). Whether the specialist or generalist is more affected depends on the global change driver in question. For example, unlike generalist herbivores, the specialist aphid Acyrthosiphon pisum is able to produce salivary metalloproteases which break down plant defensive proteins even under drought stress enabling its generalist parasitoid to maintain a high parasitism rate (Carolan et al. 2009; Nguyen et al. 2018). By contrast, habitat fragmentation more strongly impacts habitat specialists than generalists, which are able to exploit alternative hosts/habitats in the landscape (Rossetti et al. 2017).

\section{[Insert Figure 5 here]}

Figure 5. Figure 5. Potential scenarios of the impact of different drivers of global change (a: climate change, b: land use intensification and $c$ : biological invasions) on (A) populations and (B) communities of pests and parasitoids depending on host specificity. (A) Generalist pest fitness is directly or indirectly (via host-plants) more strongly affected by global change drivers (a-c) compared to specialist pests as the specialist organisms have co-evolved with their hosts. (d) Global change (a-c) enhances induction of plant secondary (defence) metabolites strongly reducing fitness of generalist pests and parasitoids through lower host (insect or plant) quality. (e) Global change does not induce plant secondary metabolites, or the generalist pest is able to excrete the toxic compounds, reducing the negative bottom-up effects compared to the (d) scenario. (f) Strong coevolution means specialist parasitoids are able to optimise and track changes in their host due to global change thereby lessening the impact. $(\mathrm{g})$ Global change elevates induction of plant secondary metabolites that specialist pests sequester, strongly lowering generalist parasitoid fitness. (h) Global change does not induce secondary metabolites, or the specialist pest is able to detoxify, reducing the negative bottom-up effects compared to the (g) scenario. (B) Specialist pest communities are affected strongly by global change compared to generalist communities because generalist species can switch hosts according to their availability. (i) Both generalist and specialist parasitoids persist in the modified environment when generalist hosts are affected only slightly by global change, although parasitoids that specialize on particular plant species/families may suffer more than true generalist parasitoids. (j) Generalist parasitoids switch to the most abundant alternative host when their specialist hosts are greatly impacted by global change. (k) Specialist parasitoids suffer greatly from global change impacts on specialist hosts. Images sourced from thenounproject.com (CC-BY: Ayumi Aya; Baboon designs; Carpe Diem; Denimao; Phạm Thanh Lộc; Varvarvarvarra).

At the population level, we suggest that parasitoids growing in specialist hosts might be less impacted by global change drivers that modulate the host physiology, compared to parasitoids growing on generalist hosts suffering from those same drivers (Figure 5A, d-f). An exception is when global change drivers induce the production of secondary metabolites in plants that are toxic to higher trophic levels, since the host specificity of both herbivores and parasitoids will dictate their ability to persist in such an environment. Indeed, a specialist herbivore will be able to detoxify or sequester these toxic compounds (Heidel-Fischer and Vogel, 2015) allowing both generalist and specialist parasitoids (detoxification) or only 
specialist parasitoids (sequestration) to maintain their population level (e.g., Chen et al. 2010; Krauss et al. 2007; Monticelli et al. 2019; Nguyen et al. 2018; Paudel et al. 2016; Sun et al. 2020). A generalist herbivore is, however, either capable of excreting toxic compounds enabling specialist and generalist parasitoids to develop normally, or they are unable to circumvent the toxicity and both their quality as hosts and their population sizes diminish with negative consequences for parasitoids (e.g., Francis et al. 2001; Monticelli et al. 2019).

When considering global change drivers impacting the herbivore community (e.g., switch in herbivore species dominance, Mohammed et al. 2019) and parasitoid habitat (e.g., fragmentation and loss of natural habitats), the population of specialist parasitoids that are highly dependent on their hosts may be more drastically impacted and may no longer be able to regulate pest populations compared to generalist parasitoids which can switch to the most dominant host (Elzinga et al. 2007) (Figure 5B, i-k). Regarding invasive species, a generalist parasitoid will have an easier time establishing itself in an environment than a specialist because it will have a greater number of potential hosts available. On the other hand, a parasitoid that is a specialist of a crop pest previously introduced into the same area will have a better chance of establishing than a generalist organism because its optimal host will be present and potentially in large quantities, if not regulated by a local natural enemy (Monticelli et al. 2021).

We could therefore recommend the use of generalist parasitoids in biocontrol programs when the herbivore community is modified by global change drivers and when the herbivores are themselves generalists because they may suffer from effect of these drivers while generalist parasitoid may be able to persist in such environment by consuming various host species. Biological control programs involving crop plants consumed by specialist herbivores may then favour both specialist and generalist organisms if plant quality is not impacted and only specialist parasitoids if the crop plant is known to produce secondary metabolites under stress. Therefore, the host specificity of both the parasitoid and their hosts should be considered, and further assessments made to determine whether specialisation is a key factor in predicting the effects of global change on parasitism with greater accuracy.

\section{CONCLUSION}

Our review shows that parasitism and biocontrol services in future landscapes are highly likely to be impacted by global change drivers. Land use intensification is associated with the use of large proportions of land masses for agriculture which is supported by high levels of inputs. For the associated phenomena of habitat loss, erosion of biodiversity and agrochemical use there is strong evidence of adverse effects on parasitoid individuals, assemblages and function though there is a paucity of research on the effects on hyperparasitoids (parasitoids 
that attack parasitoids) (Figure 6). Further effort to confirm these effects under field conditions is still needed to solidify the conclusions and identify the underlying mechanisms (Figure 6). Loss of biocontrol services as a result of intensification can entrench usage of insecticides though there is growing research efforts into habitat manipulation approaches at the field or landscape scale to reinstate parasitoid function. Climate change can affect parasitoids directly, affecting aspects such as development time and survival, as well as indirectly via phenological and other effects on their hosts, on endosymbionts, and on the first trophic level via changes to plant chemistry and host-plant defences including herbivore-induced plant volatiles (HIPVs). Whilst major, direct effects are often well studied, the complexity of potential community level interaction permutations lead to many knowledge gaps and impaired capacity to predict the effects of climate change (Figure 6). Biological invasions have increased dramatically with increased human travel and trade, introducing alien species to vulnerable recipient regions that were formerly isolated and with incompletely occupied niches. In this context, parasitoid use in biocontrol is especially important to combat host (pest) insects that have previously been translocated and released from control by enemies from their native range. But the effects of alien species are often not easily remedied and include negative effects on native parasitoids when, for example, an invasive herbivore triggers the production of HIPVs that are not recognised by native parasitoids and even disrupts their capacity to utilise native hosts (Figure 6).

Impact of global change drivers on biodiversity loss are biome-dependent and increased land use appears to be the driver with the strongest impact, followed by climate change, nitrogen use, and biological invasions (IPBES 2019). When considering the impact of global change drivers on parasitoids and their ability to regulate pest populations, it would appear that the major driver is climate change represented by an increase in temperature.

Potentially important interactions can occur among each of the three major forms of global change. For example, regional temperature increase resulting from climate change can facilitate invasions; and the effects of temperature can affect biological responses to agricultural inputs such as nitrogen. A major challenge for ecologists seeking to understand the extent of global change phenomena is the multitude of direct and indirect interactions that may occur at species and community levels. Simple, predictable additive effects appear to be

1214 rare, and difficulties in making predictions are compounded by the fact that effects can occur 1215 at spatial scales ranging from microhabitat to biome (Figure 6). Addressing this challenge in future studies might be made more tractable by focusing on parasitoids and the biocontrol services they provide. The high level of host specificity generally exhibited by parasitoids simplifies the extent of potential interactions and makes them a useful taxon for studies of wider effects on other taxa. It is, however, rarely considered and further studies and reviews incorporating parasitoid host specificity as a key driver explaining the impact of global change 
1221 drivers on parasitoids and their role as biocontrol agents are therefore needed (Figure 6).

1222 Moreover, the long-recognised economic value of parasitoids in biocontrol programs, some

1223 dating back well over a century, provides both the incentive to invest in research and a rich

1224 evidence base from which effects on other taxa may be predicted.

\section{[Insert Figure 6 here]}

Figure 6. Confidence in the evidence-base for impacts on host-parasitoid interactions of global change drivers, their interactions, and the role of organism specificity in modulating those impacts. The degree of confidence in each impact (black dot) is based on the quantity and quality of the evidence in the literature reviewed, and the level of agreement between studies using a four-box model for the qualitative communication of confidence (IPBES, 2019). Confidence increases towards the top-right corner as suggested by the increasing strength of shading. The terms are: Well established: comprehensive meta-analysis or other synthesis or multiple independent studies that agree. Established but incomplete: general agreement although only a limited number of studies exist; no comprehensive synthesis and/or the studies that exist address the question imprecisely. Unresolved: multiple independent studies exist but conclusions do not agree. Inconclusive: limited evidence, recognizing major knowledge gaps. 
1241 Bottom-up effect: the bottom-up effect is defined as the effect occurring from lower trophic 1242 levels affecting the higher trophic level.

1243 Conventional agricultural intensification: Mechanized livestock management on an 1244 industrial scale and large-scale monocultures in simplified rotations of high-yielding varieties 1245 (including GMOs) that are dependent on agricultural inputs (fertilizers, pesticides).

1246 Diploid: Diploid organisms have chromosomes in pairs ( $2 n$ chromosomes). Haploid 1247 organisms have chromosomes in single copies ( $n$ chromosomes).

1248 Ecosystem services: Benefits from ecosystems including provisioning services or goods 1249 (e.g., food, timber, water), essential regulating services mediated by biodiversity (e.g., crop 1250 pollination, soil erosion prevention, water purification), and cultural services (e.g., recreation, 1251 sense of place).

1252 Food chain: sequence of transfers of matter and energy in the form of food from organism to 1253 organism.

1254 Food web: interconnection of food chains.

1255 Haplodiploid: Haplodiploidy characterizes a sex-determination mode in which males develop 1256 from an unfertilized egg and females from a fertilized egg.

1257 Organism fitness: describes individual reproductive success.

1258 Host specificity: both the range and diversity of host species.

1259 Idiobiont: female parasitoid kills or permanently paralyzes the host during oviposition, thus 1260 stopping its development.

1261 Integrated pest management: Pesticides should be used as a last resort and only when an 1262 economic threshold of pest damage has been crossed. The use of less toxic products such 1263 as biocontrol should be favored.

1264 Inundative biocontrol: release of large numbers of mass-produced biological control agents 1265 to reduce the population of a pest.

1266 Kairomones: substance produced by a living being (transmitter), released into the 1267 environment, which triggers a response in another species (receiver), providing a benefit to 1268 the latter.

1269 Koinobiont: a parasitoid whose host continues to feed and grow after parasitisation.

1270 Landscape composition: landscape spatial characteristics studied when measuring the 1271 arrangements, the positions and the orientations of the different landscape patches.

1272 Landscape configuration: variability and abundance of the different landscape attributes.

1273 Phenology: science that studies the influence of climatic variations on periodic phenomena 1274 in the life of organisms.

1275 Plant inter-specific diversity: refers to plant species diversity.

1276 Plant intra-specific diversity: refers to plant genotypic or phenotypic diversity. 
1277 Pro-ovigenic: eggs available for oviposition by pro-ovigenic parasitoids are mature at the time 1278 of emergence or mature very quickly after emergence.

1279 Synovigenic: the maturation of the eggs is carried out throughout the life of the adult and the 1280 number of eggs produced depends on carbohydrate sources.

1281 Top-down regulation: the top-down force refers to the impact of the higher trophic level 1282 regulating the lower trophic level. 


\section{REFERENCES}

Abarca M and Lill JT. 2019. Latitudinal variation in the phenological responses of eastern tent caterpillars and their egg parasitoids. Ecological Entomology 44, 50-61.

Abarca M and Spahn R. 2021. Direct and indirect effects of altered temperature regimes and phenological mismatches on insect populations. Current Opinion in Insect Science 47,6774.

Abram, P. K., Gariepy, T. D., Boivin, G. \& Brodeur, J. 2014. An invasive stink bug as an evolutionary trap for an indigenous egg parasitoid. Biological Invasions, 16, 1387-1395.

Agosta SJ, Joshi KA and Kester KM. 2018. Upper thermal limits differ among and within component species in a tritrophic host-parasitoid-hyperparasitoid system. PLoS ONE 13, $1-15$.

Ahmed SS, Liu D and Simon J-C. 2017. Impact of water-deficit stress on tritrophic interactions in a wheat-aphid-parasitoid system. PLOS ONE 12, 1-17.

Alford L, Louâpre P, Mougel F and van Baaren J. 2020. Measuring the evolutionary potential of a winter-active parasitic wasp to climate change. Oecologia 194, 41-50.

Alves, T. J. S., Murcia, A., Wanumen, A. C., Wanderley-Teixeira, V., Teixeira, Á. A. C., Ortiz, A., \& Medina, P. 2019. Composition and Toxicity of a Mixture of Essential Oils Against Mediterranean Fruit Fly, Ceratitis capitata (Wiedemann) (Diptera: Tephritidae). Journal of Economic Entomology, 112(1), 164-172.

Asadi, M., Rafiee-Dastjerdi, H., Nouri-Ganbalani, G., Naseri, B., \& Hassanpour, M. 2019. Lethal and sublethal effects of five insecticides on the demography of a parasitoid wasp. International Journal of Pest Management, 65(4), 301-312.

Aslam TJ, Johnson SN and Karley AJ. 2013. Plant-mediated effects of drought on aphid population structure and parasitoid attack. Journal of Applied Entomology 137, 136-145.

Asplen MK, Anfora G, Biondi A, Choi DS, Chu D, Daane KM, Gibert P, Gutierrez AP, Hoelmer KA, Hutchison WD, Isaacs R, Jiang ZL, Karpati Z, Kimura MT, Pascual M, Philips CR, Plantamp C, Ponti L, Vetek G, Vogt H, Walton VM, Yu Y, Zappala L, Desneux N. 2015. Invasion biology of spotted wing drosophila (Drosophila suzukii): a global perspective and future priorities. J Pest Sci $88,469-494$.

Audusseau H, Ryrholm N, Stefanescu C, Tharel S, Jansson C, Champeaux L, Shaw MR, Raper C, Lewis OT, Janz N and Schmucki R. 2021. Rewiring of interactions in a changing environment: nettle-feeding butterflies and their parasitoids. Oikos 130, 624-636.

Awmack, C. S., \& Leather, S. R. 2002. Host plant quality and fecundity in herbivorous insects. In Annual Review of Entomology. Vol. 47, pp. 817-844. Annual Reviews 4139 El Camino Way, P.O. Box 10139, Palo Alto, CA 94303-0139, USA .

Bale JS and Hayward SAL. 2010. Insect overwintering in a changing climate. Journal of Experimental Biology 213, 980-994. 
1321

1322

1323

1324

1325

1326

1327

1328

1329

1330

1331

1332

1333

1334

1335

1336

1337

1338

1339

1340

1341

1342

1343

1344

1345

1346

1347

1348

1349

1350

1351

1352

1353

1354

1355

1356

Barbosa, P., Gross, P., \& Kemper, J. 1991. Influence of plant allelochemicals on the tobacco hornworm and its parasitoid, Cotesia congregata. Ecology, 72(5), 1567-1575.

Baude, M., Meyer, B. C., \& Schindewolf, M. 2019. Land use change in an agricultural landscape causing degradation of soil based ecosystem services. Science of the Total Environment, 659, 1526-1536.

Bayram, A., Salerno, G., Onofri, A., \& Conti, E. 2010. Sub-lethal effects of two pyrethroids on biological parameters and behavioral responses to host cues in the egg parasitoid Telenomus busseolae. Biological Control, 53(2), 153-160.

Becker, C., Desneux, N., Monticelli, L., Fernandez, X., Michel, T., \& Lavoir, A.-V. 2015. Effects of abiotic factors on HIPV-mediated interactions between plants and parasitoids. BioMed Research International, 2015.

Bell JR, Alderson L, Izera D, Kruger T, Parker S, Pickup J, Shortall CR, Taylor MS, Verrier P and Harrington R. 2015. Long-term phenological trends, species accumulation rates, aphid traits and climate: five decades of change in migrating aphids. Journal of Animal Ecology 84, 21-34.

Benelli, G., Giulia Giunti, B., Alejandro Tena, B., Nicolas Desneux, B., Alice Caselli, B., \& Angelo Canale, B. 2017. The impact of adult diet on parasitoid reproductive performance. Journal of Pest Science, 90, 807-823.

Bensadia F, Boudreault S, Guay J-F, Michaud D and Cloutier C. 2006. Aphid clonal resistance to a parasitoid fails under heat stress. Journal of Insect Physiology 52, 146-157.

Berger, J. S., Birkhofer, K., Hanson, H. I., \& Hedlund, K. 2018. Landscape configuration affects herbivore-parasitoid communities in oilseed rape. Journal of Pest Science, 91(3), 10931105.

Bezemer TM, Jones TH and Knight KJ. 1998. Long-term effects of elevated CO2 and temperature on populations of the peach potato aphid Myzus persicae and its parasitoid Aphidius matricariae. Oecologia 116, 128-135.

Biale, H., Geden, C. J., Chiel, E., \& Fryxell, R. T. 2020. Heat Adaptation of the House Fly (Diptera: Muscidae) and Its Associated Parasitoids in Israel. Journal of Medical Entomology, 57(1), 113-121.

Bianchi, F. J. J. A., Booij, C. J. H., \& Tscharntke, T. 2006. Sustainable pest regulation in agricultural landscapes: A review on landscape composition, biodiversity and natural pest control. In Proceedings of the Royal Society B: Biological Sciences (Vol. 273, Issue 1595, pp. 1715-1727). Royal Society.

Biondi, A., Zappalà, L., Stark, J. D., \& Desneux, N. 2013. Do Biopesticides Affect the Demographic Traits of a Parasitoid Wasp and Its Biocontrol Services through Sublethal Effects? PLOS ONE, 8(9). 
Biondi A, Guedes RNC, Wan FH, Desneux N. 2018. Ecology, worldwide spread, and management of the invasive South American tomato pinworm, Tuta absoluta: past, present, and future. Annu Rev Entomol 63,239-258.

Blackburn, T. M., Pyšek, P., Bacher, S., Carlton, J. T., Duncan, R. P., Jarošík, V., Wilson, J. R. U., \& Richardson, D. M. 2011. A proposed unified framework for biological invasions. In Trends in Ecology and Evolution, 26(7), 333-339.

Bonsignore CP, Vizzari G, Vono G and Bernardo U. 2020. Short-term cold stress affects parasitism on the Asian chestnut gall wasp Dryocosmus kuriphilus. Insects 11, 841.

Bonsignore CP, Vono $\mathrm{G}$ and Bernardo U. 2019. Environmental thermal levels affect the phenological relationships between the chestnut gall wasp and its parasitoids. Physiological Entomology 44, 87-98.

Boughton, A. J., Mendez, M. A., Francis, A. W., Smith, T. R., Osborne, L. S. \& Mannion, C. M. 2015. Host stage suitability and impact of Encarsia noyesi (Hymenoptera: Aphelinidae) on the invasive rugose spiraling whitefly, Aleurodicus rugioperculatus (Hemiptera: Aleyrodidae), in Florida. Biological Control, 88, 61-67.

Bueno, A. de F., Bueno, R. C. O. de F., Parra, J. R. P., \& Vieira, S. S. 2008. Effects of pesticides used in soybean crops to the egg parasitoid Trichogramma pretiosum. Ciência Rural, 38(6), 1495-1503.

Butler CD, Beckage NE and Trumble JT. 2009. Effects of terrestrial pollutants on insect parasitoids. Environmental Toxicology and Chemistry 28, 1111-1119.

Calatayud P, Polanía M, Seligmann C and Bellotti A. 2002. Influence of water-stressed cassava on Phenacoccus herreni and three associated parasitoids. Entomologia Experimentalis et Applicata 102, 163-175.

Campbell, B. C., \& Duffey, S. S. 1979. Tomatine and parasitic wasps: potential incompatibility of plant antibiosis with biological control. Science, 205(4407), 700-702.

Capinha, C., Essl, F., Seebens, H., Moser, D., \& Pereira, H. M. 2015. The dispersal of alien species redefines biogeography in the Anthropocene. Science, 348(6240), 1248-1251.

Carolan, J. C., Fitzroy, C. I., Ashton, P.D., Douglas, A. E., Wilkinson, T.L. 2009. The secreted salivary proteome of the pea aphid Acyrthosiphon pisum characterised by mass spectrometry. Proteomics, 9(9), 2457-2467.

Carrasco, D., Desurmont, G. A., Laplanche, D., Proffit, M., Gols, R., Becher, P. G., Larsson, M. C., Turlings, T. C. J., \& Anderson, P. 2018. With or without you: Effects of the concurrent range expansion of an herbivore and its natural enemy on native species interactions. Global Change Biology, 24(2), 631-643.

Carvalheiro, L. G., Buckley, Y. M. \& Memmott, J. 2010. Diet breadth influences how the impact of invasive plants is propagated through food webs. Ecology, 91, 1063-1074. 
1393

Castex V, Beniston M, Calanca P, Fleury D and Moreau J. 2018. Pest management under climate change: The importance of understanding tritrophic relations. Science of The Total Environment 616-617, 397-407.

Chabert, S., Allemand, R., Poyet, M., Eslin, P. \& Gibert, P. 2012. Ability of European parasitoids (Hymenoptera) to control a new invasive Asiatic pest, Drosophila suzukii. Biological Control, 63, 40-47.

Chailleux A, Mohl EK, Teixeira Alves M, Messelink GJ, Desneux N. 2014. Natural enemymediated indirect interactions among prey species: potential for enhancing biocontrol services in agroecosystems Pest. Manage Sci $70,1769-1779$.

Challinor, A. J., Watson, J., Lobell, D. B., Howden, S. M., Smith, D. R., \& Chhetri, N. 2014. A meta-analysis of crop yield under climate change and adaptation. Nature Climate Change 2014 4:4, 4(4), 287-291.

Chen, Y., Olson, D. M., \& Ruberson, J. R. 2010. Effects of nitrogen fertilization on tritrophic interactions. In Arthropod-Plant Interactions (Vol. 4, Issue 2, pp. 81-94). Springer.

Chen, Y.-Z., Lin, L., Wang, C.-W., Yeh, C.-C., \& Hwang, S.-Y. 2004. Response of Two Pieris (Lepidoptera: Pieridae) Species to Fertilization of a Host Plant. Zoological Studies, 43(4), 778-786.

Chen C, Donner SH, Biere A, Gols R and Harvey JA. 2019. Simulated heatwave conditions associated with global warming affect development and competition between hyperparasitoids. Oikos 128, 1783-1792.

Cheng, S., Lin, R., Yu, C., Sun, R., \& Jiang, H. 2021. Toxic effects of seven pesticides to aphid parasitoid, Aphidius gifuensis (Hymenoptera: Braconidae) after contact exposure. Crop Protection, 145.

Chesnais, Q., Couty, A., Catterou, M., \& Ameline, A. 2016. Cascading effects of $\mathrm{N}$ input on tritrophic (plant-aphid-parasitoid) interactions. Ecology and Evolution, 6(21), 7882-7891.

Cipollini, D. F., \& Bergelson, J. 2001. Plant density and nutrient availability constrain constitutive and wound-induced expression of trypsin inhibitors in Brassica napus. Journal of Chemical Ecology, 27(3), 593-610.

Cloyd, R. 2012. Indirect Effects of Pesticides on Natural Enemies. In Pesticides - Advances in Chemical and Botanical Pesticides. InTech.

Cooper, J., \& Dobson, H. 2007. The benefits of pesticides to mankind and the environment. In Crop Protection (Vol. 26, Issue 9, pp. 1337-1348). Elsevier.

Corbin C, Heyworth ER, Ferrari $\mathrm{J}$ and Hurst GD. 2017. Heritable symbionts in a world of varying temperature. Heredity 118, 10-20.

Corcos, D., Cerretti, P., Mei, M., Vigna Taglianti, A., Paniccia, D., Santoiemma, G., De Biase, A., \& Marini, L. 2018. Predator and parasitoid insects along elevational gradients: role of temperature and habitat diversity. Oecologia, 188(1), 193-202. 
1430 Cowles, R. S., \& Eitzer, B. D. 2017. Residues of neonicotinoid insecticides in pollen and nectar from model plants. Journal of Environmental Horticulture, 35(1), 24-34.

Crain, C. M., Kroeker, K., \& Halpern, B. S. 2008. Interactive and cumulative effects of multiple human stressors in marine systems. Ecology Letters, 11(12), 1304-1315.

D’Ávila, V. A., Barbosa, W. F., Guedes, R. N. C., \& Christopher Cutler, G. 2018. Effects of spinosad, imidacloprid, and lambda-cyhalothrin on survival, parasitism, and reproduction of the aphid parasitoid aphidius colemani. Journal of Economic Entomology, 111(3), 10961103.

Damien M and Tougeron K. 2019. Prey-predator phenological mismatch under climate change. Current Opinion in Insect Science 35, 60-68.

Darling, E. S., \& Côté, I. M. 2008. Quantifying the evidence for ecological synergies. Ecology Letters, 11(12), 1278-1286.

Darrow, K., \& Bowers, M. D. 1999. Effects of herbivore damage and nutrient level on induction of iridoid glycosides in Plantago lanceolata. Journal of Chemical Ecology, 25(6), 14271440.

David, P., Thebault, E., Anneville, O., Duyck, P. F., Chapuis, E. \& Loeuille, N. 2017. Impacts of Invasive Species on Food Webs: A Review of Empirical Data. In: BOHAN, D. A., DUMBRELL, A. J. \& MASSOL, F. (eds.) Networks of Invasion: A Synthesis of Concepts.

Dawson, W., Moser, D., van Kleunen, M., Kreft, H., Pergl, J., Pyšek, P., Weigelt, P., Winter, M., Lenzner, B., Blackburn, T. M., Dyer, E. E., Cassey, P., Scrivens, S. L., Economo, E. P., Guénard, B., Capinha, C., Seebens, H., García-Díaz, P., Nentwig, W., García-Berthou, E., Casal, C., Mandrak, N. E., Fuller, P., Meyer, C. \& Essl, F. 2017. Global hotspots and correlates of alien species richness across taxonomic groups. Nature, Ecology \& Evolution $1,0186$.

De Moraes, C. M., Lewis, W. J., Pare, P. W., Alborn, H. T., \& Tumiinson, J. H. 1998. Herbivoreinfested plants selectively attract parasitoids. Nature, 393(6685), 570-573.

de Sassi, C., Staniczenko, P. P. A., \& Tylianakis, J. M. 2012. Warming and nitrogen affect size structuring and density dependence in a host-parasitoid food web. Philosophical Transactions of the Royal Society B: Biological Sciences, 367(1605), 3033-3041.

Delpuech, J. M., Frey, F., \& Carton, Y. 1996. Action of insecticides on the cellular immune reaction of Drosophila melanogaster against the parasitoid Leptopilina boulardi. Environmental Toxicology and Chemistry, 15(12), 2267-2271.

Denis D, van Baaren J, Pierre J-S and Wajnberg E. 2013. Evolution of a physiological tradeoff in a parasitoid wasp: how best to manage lipid reserves in a warming environment. Entomologia Experimentalis et Applicata 148, 27-38. 
Derocles SAP, Lunt DH, Berthe SCF, Nichols PC, Moss ED and Evans DM. 2018. Climate warming alters the structure of farmland tritrophic ecological networks and reduces crop yield. Molecular Ecology 27, 4931-4946.

Desneux, N., Wajnberg, E., Fauvergue, X., Privet, S., \& Kaiser, L. 2004a. Oviposition behaviour and patch-time allocation in two aphid parasitoids exposed to deltamethrin residues. Entomologia Experimentalis et Applicata, 112(3), 227-235.

Desneux N, Rafalimanana H, Kaiser L. 2004b. Dose-response relationship in lethal and behavioural effects of different insecticides on the parasitic wasp Aphidius ervi. Chemosphere 54, 619-627.

Desneux N, Pham-Delegue MH, Kaiser L. 2004c. Effects of sub-lethal and lethal doses of lambda cyhalothrin on oviposition experience and host-searching behaviour of a parasitic wasp, Aphidius ervi. Pest Manag Sci 60, 381-389

Desneux N, Fauvergue X, Dechaume-Moncharmont F-X, Kerhoas L, Ballanger Y, Kaiser L. 2005. Diaeretiella rapae limits Myzus persicae populations after applications of deltamethrin in oilseed rape. J Econ Entomol 98, 9-17.

Desneux, N., Denoyelle, R., \& Kaiser, L. 2006a. A multi-step bioassay to assess the effect of the deltamethrin on the parasitic wasp Aphidius ervi. Chemosphere, 65(10), 1697-1706.

Desneux N, Ramirez-Romero R, Kaiser L. 2006b. Multistep bioassay to predict recolonization potential of emerging parasitoids after a pesticide treatment. Environ Toxicol Chem 25, 2675-2682.

Desneux, N., Decourtye, A., \& Delpuech, J. M. 2007. The sublethal effects of pesticides on beneficial arthropods. In Annual Review of Entomology (Vol. 52, pp. 81-106). Annual Reviews.

Desneux N, Wajnberg E, Wyckhuys KAG, Burgio G et al. 2010. Biological invasion of European tomato crops by Tuta absoluta: ecology, geographic expansion and prospects for biological control. J Pest Sci 83,197-215.

Despland, E. \& Santacruz, P. G. 2020. Top-down and bottom-up controls on an herbivore on a native and introduced plant in a tropical agricultural landscape. Peerj, 8.

Desurmont, G. A., Harvey, J., Van Dam, N. M., Cristescu, S. M., Schiestl, F. P., Cozzolino, S., Anderson, P., Larsson, M. C., Kindlmann, P., Danner, H. \& Turlings, T. C. J. 2014. Alien interference: disruption of infochemical networks by invasive insect herbivores. Plant, Cell \& Environment, 37, 1854-1865.

Díaz, S., Settele, J., Brondízio, E. S., Ngo, H. T., Agard, J., Arneth, A., Balvanera, P., Brauman, K. A., Butchart, S. H. M., Chan, K. M. A., Garibaldi, L. A., Ichii, K., Liu, J., Subramanian, S. M., Midgley, G. F., Miloslavich, P., Molnár, Z., Obura, D., Pfaff, A., Polasky, S., Purvis, A., Razzaque, J., Reyers, B., Chowdhury, R. R., Shin, Y.-J., Visseren- 
Hamakers, I., Willis, K. J. \& Zayas, C. N. 2019. Pervasive human-driven decline of life on Earth points to the need for transformative change. Science, 366, eaax3100.

Dicke M and Baldwin IT. 2010. The evolutionary context for herbivore-induced plant volatiles, beyond the 'cry for help'. Trends in Plant Science 15, 167-175.

van Doan C, Pfander M, Guyer AS, Zhang X, Maurer C and Robert CA. 2021. Natural enemies of herbivores maintain their biological control potential under short-term exposure to future CO2, temperature, and precipitation patterns. Ecology and Evolution 11, 4182-4192.

Dominik, C., Seppelt, R., Horgan, F. G., Settele, J., \& Václavík, T. 2018. Landscape composition, configuration, and trophic interactions shape arthropod communities in rice agroecosystems. Journal of Applied Ecology, 55(5), 2461-2472.

Du Y, Poppy GM, Powell W, Pickett JA, Wadhams LJ and Woodcock CM. 1998. Identification of semiochemicals released during aphid feeding that attract parasitoid Aphidius ervi. Journal of Chemical Ecology 24, 1355-1368.

Duan JJ, Bauer LS, Van Driesche R, Schmude JM, Petrice T, Chandler JL and Elkinton J. 2020. Effects of extreme low winter temperatures on the overwintering survival of the introduced larval parasitoids Spathius galinae and Tetrastichus planipennisi: implications for biological control of Emerald ash borer in North America. Journal of Economic Entomology 113, 1145-1151.

Duan JJ, Jennings DE, Williams DC and Larson KM. 2014. Patterns of parasitoid host utilization and development across a range of temperatures: implications for biological control of an invasive forest pest. BioControl 59, 659-669.

Dudt, J. F., \& Shure, D. J. 1994. The influence of light and nutrients on foliar phenolics and insect herbivory. Ecology, 75(1), 86-98.

Duffey, \& Ss. 1986. Consequences of sequestration of plant natural products in plant-insectparasitoid interactions. Interactions of Plant Resistance and Parasitoids and Predatory of Insects, 31-60.

Dyer LA, Richards LA, Short SA and Dodson CD. 2013. Effects of CO2 and temperature on tritrophic interactions. PLOS ONE 8, 1-9.

Early, R., Bradley, B. A., Dukes, J. S., Lawler, J. J., Olden, J. D., Blumenthal, D. M., Gonzalez, P., Grosholz, E. D., Ibañez, I., Miller, L. P., Sorte, C. J. B., \& Tatem, A. J. 2016. Global threats from invasive alien species in the twenty-first century and national response capacities. Nature Communications, 7(1), 16.

Elliott, N., Brewer, M. J., Giles K. L. 2018. Landscape Context Affects Aphid Parasitism by Lysiphlebus testaceipes (Hymenoptera: Aphidiinae) in Wheat Fields. Academic.Oup.Com. Retrieved June 25, 202. 
1536

Elzinga, J. A., van Nouhuys, S., van Leeuwen, D. J., \& Biere, A. 2007. Distribution and colonisation ability of three parasitoids and their herbivorous host in a fragmented landscape. Basic and Applied Ecology, 8(1), 75-88.

Evans EW, Carlile NR, Innes MB and Pitigala N. 2013. Warm springs reduce parasitism of the cereal leaf beetle through phenological mismatch. Journal of Applied Entomology 137, 383391.

Ewald, J. A., Wheatley, C. J., Aebischer, N. J., Moreby, S. J., Duffield, S. J., Crick, H. Q. P., \& Morecroft, M. B. 2015. Influences of extreme weather, climate and pesticide use on invertebrates in cereal fields over 42 years. Global Change Biology, 21(11), 3931-3950.

Facey SL, Ellsworth DS, Staley JT, Wright DJ and Johnson SN. 2014. Upsetting the order: how climate and atmospheric change affects herbivore-enemy interactions. Current Opinion in Insect Science 5, 66-74.

Fahrig, L., Baudry, J., Brotons, L., Burel, F. G., Crist, T. O., Fuller, R. J., Sirami, C., Siriwardena, G. M., \& Martin, J. L. 2011. Functional landscape heterogeneity and animal biodiversity in agricultural landscapes. Ecology Letters, 14(2), 101-112.

Feit, B., Blüthgen, N., Daouti, E., Straub, C., Traugott, M., \& Jonsson, M. 2021. Landscape complexity promotes resilience of biological pest control to climate change. Proceedings of the Royal Society B, 288(1951).

Flores-Mejia S, Fournier V and Cloutier C. 2017. Performance of a tri-trophic food web under different climate change scenarios. Food Webs 11, 1-12.

Foley, J. A., DeFries, R., Asner, G. P., Barford, C., Bonan, G., Carpenter, S. R., Chapin, F. S., Coe, M. T., Daily, G. C., Gibbs, H. K., Helkowski, J. H., Holloway, T., Howard, E. A., Kucharik, C. J., Monfreda, C., Patz, J. A., Prentice, I. C., Ramankutty, N., \& Snyder, P. K. 2005. Global consequences of land use. In Science (Vol. 309, Issue 5734, pp. 570-574). American Association for the Advancement of Science.

Fontes, J., Roja, I. S., Tavares, J., \& Oliveira, L. 2018. Lethal and sublethal effects of various pesticides on trichogramma achaeae (hymenoptera: Trichogrammatidae). Journal of Economic Entomology, 111(3), 1219-1226.

Foray V, Desouhant $E$ and Gibert P. 2014. The impact of thermal fluctuations on reaction norms in specialist and generalist parasitic wasps. Functional Ecology 28, 411-423.

Forrest JR. 2016. Complex responses of insect phenology to climate change. Current Opinion in Insect Science 17, 49-54.

Frago, E., Pujade-Villar, J., Guara, M., \& Selfa, J. 2012. Hyperparasitism and seasonal patterns of parasitism as potential causes of low top-down control in Euproctis chrysorrhoea L. (Lymantriidae). Biological Control, 60(2), 123-131. 
1571

1572

1573

1574

1575

1576

1577

1578

1579

1580

1581

1582

1583

1584

1585

1586

1587

1588

1589

1590

1591

1592

1593

1594

1595

1596

1597

1598

1599

1600

1601

1602

1603

1604

1605

1606

Frago E, Mala M, Weldegergis BT, Yang C, McLean A, Godfray HCJ, Gols R and Dicke M. 2017. Symbionts protect aphids from parasitic wasps by attenuating herbivore-induced plant volatiles. Nature Communications 8, 1860.

Francis, F., Lognay, G., Wathelet, J.-P., \& Haubruge, E. 2001. Effects of Allelochemicals from First (Brassicaceae) and Second (Myzus persicae and Brevicoryne brassicae) Trophic Levels on Adalia bipunctata. Journal of Chemical Ecology 2001 27:2, 27(2), 243-256.

Frost, C. M., Allen, W. J., Courchamp, F., Jeschke, J. M., Saul, W. C. \& Wardle, D. A. 2019. Using Network Theory to Understand and Predict Biological Invasions. Trends in Ecology \& Evolution, 34, 831-843.

Frost, C. M., Peralta, G., Rand, T. A., Didham, R. K., Varsani, A. \& Tylianakis, J. M. 2016. Apparent competition drives community-wide parasitism rates and changes in host abundance across ecosystem boundaries. Nature Communications, 7.

Furlong MJ and Zalucki MP. 2017. Climate change and biological control: the consequences of increasing temperatures on host-parasitoid interactions. Current Opinion in Insect Science 20, 39-44.

Gagic, V., Hänke, S., Thies, C., Scherber, C., Eljko Tomanovic', Z. `, Tomanovic', T., \& Tscharntke, T. 2012. Agricultural intensification and cereal aphid-parasitoidhyperparasitoid food webs: network complexity, temporal variability and parasitism rates. Oecologia. 170, 1099-1109.

Gagic, V., Hänke, S., Thies, C., \& Tscharntke, T. 2014. Community variability in aphid parasitoids versus predators in response to agricultural intensification. Insect Conservation and Diversity, 7(2), 103-112.

Gate IM, McNeill S and Ashmore MR. 1995. Effects of air pollution on the searching behaviour of an insect parasitoid. Water, Air, and Soil Pollution 85, 1425-1430.

Gerard P. 2004. Synchronisation of the parasitoid Centrodora scolypopae with its host Scolypopa australis. New Zealand Plant Protection 57, 191-195.

Gharekhani, G., Salehi, F., Shirazi, J., \& Vaez, N. 2020. Tri-trophic interactions among nitrogen-fertilized tomato cultivars, the tomato fruit worm, Helicoverpa armigera (Hübner) (Lepidoptera: Noctuidae) and the ectoparasitoid, Habrobracon hebetor (Say) (Hymenoptera: Braconidae). Egyptian Journal of Biological Pest Control, 30(1).

Gillespie DR, Nasreen A, Moffat CE, Clarke P and Roitberg BD. 2012. Effects of simulated heat waves on an experimental community of pepper plants, green peach aphids and two parasitoid species. Oikos 121, 149-159.

Gillespie, M. A. K., Gurr, G. M., \& Wratten, S. D. 2016. Beyond nectar provision: the other resource requirements of parasitoid biological control agents. Wiley Online Library, 159(2), 207-221. 
1607

Godfray HC. 1994. Parasitoids: behavioral and evolutionary ecology. Princeton University Press.

Gould JR, Warden ML, Slager BH and Murphy TC. 2020. Host overwintering phenology and climate change influence the establishment of Tetrastichus planipennisi Yang (Hymenoptera: Eulophidae), a larval parasitoid introduced for biocontrol of the Emerald ash borer. Journal of Economic Entomology 113, 2641-2649.

Grab, H., Danforth, B., Poveda, K., \& Loeb, G. 2018. Landscape simplification reduces classical biological control and crop yield. Ecological Applications, 28(2), 348-355.

Grabenweger, G., Kehrli, P., Zweimuller, I., Augustin, S., Avtzis, N., Bacher, S., Freise, J., Girardoz, S., Guichard, S., Heitland, W., Lethmayer, C., Stolz, M., Tomov, R., Volter, L. \& Kenis, M. 2010. Temporal and spatial variations in the parasitoid complex of the horse chestnut leafminer during its invasion of Europe. Biological Invasions, 12, 2797-2813.

Guay J-F, Boudreault S, Michaud D and Cloutier C. 2009. Impact of environmental stress on aphid clonal resistance to parasitoids: Role of Hamiltonella defensa bacterial symbiosis in association with a new facultative symbiont of the pea aphid. Journal of Insect Physiology 55, 919-926.

Guedes, R. N. C., Smagghe, G., Stark, J. D., \& Desneux, N. 2016. Pesticide-Induced Stress in Arthropod Pests for Optimized Integrated Pest Management Programs. In Annual Review of Entomology. 61, 43-62.

Guedes, R. N. C., Walse, S. S., \& Throne, J. E. 2017. Sublethal exposure, insecticide resistance, and community stress. In Current Opinion in Insect Science. 21, 47-53.

Gurr, G. M., Wratten, S. D., Landis, D. A., \& You, M. 2017. Habitat Management to Suppress Pest Populations: Progress and Prospects. In Annual Review of Entomology. 62, 91-109.

Haan, N., Zhang, Y., Douglas A. L. 2020. Predicting landscape configuration effects on agricultural pest suppression. Trends in Ecology \& Evolution. 35(2), 175-186.

Haile, M. G., Wossen, T., Tesfaye, K., \& von Braun, J. 2017. Impact of Climate Change, Weather Extremes, and Price Risk on Global Food Supply. Economics of Disasters and Climate Change 2017 1:1, 1(1), 55-75.

Han, P., Lavoir, A. V., Le Bot, J., Amiens-Desneux, E., \& Desneux, N. 2014. Nitrogen and water availability to tomato plants triggers bottom-up effects on the leafminer Tuta absoluta. Scientific Reports, 4(1), 1-8.

Han Z, Tan X, Wang Y, Xu Q, Zhang Y, Harwood JD and Chen J. 2019. Effects of simulated climate warming on the population dynamics of Sitobion avenae (Fabricius) and its parasitoids in wheat fields. Pest Management Science 75, 3252-3259.

Hance T, van Baaren J, Vernon P and Boivin G. 2007. Impact of extreme temperatures on parasitoids in a climate change perspective. Annual Review of Entomology 52, 107-126. 
1643

1644

1645

1646

1647

1648

1649

1650

1651

1652

1653

1654

1655

1656

1657

1658

1659

1660

1661

1662

1663

1664

1665

1666

1667

1668

1669

1670

1671

1672

1673

1674

1675

1676

1677

1678

1679

Harkness, C., Areal, F. J., Semenov, M. A., Senapati, N., Shield, I. F., \& Bishop, J. 2021. Stability of farm income: The role of agricultural diversity and agri-environment scheme payments. Agricultural Systems, 187, 103009.

Harvey JA. 2015. Conserving host-parasitoid interactions in a warming world. Current Opinion in Insect Science 12, 79-85.

Hawro, V., Ceryngier, P., Kowalska, A., \& Ulrich, W. 2016. Landscape structure and agricultural intensification are weak predictors of host range and parasitism rate of cereal aphids. Springer.

Hawro, V., Ceryngier, P., Tscharntke, T., Thies, C., Gagic, V., Bengtsson, J., Bommarco, R., Winqvist, C., Weisser, W. W., Clement, L. W., Japoshvili, G., \& Ulrich, W. 2015. Landscape complexity is not a major trigger of species richness and food web structure of European cereal aphid parasitoids. BioControl, 60(4), 451-461.

Heimpel, G. E., \& Mills, N. J. 2017. Biological control: Ecology and applications. In Biological Control: Ecology and Applications. Cambridge University Press.

Heidel-Fischer, H. M., \& Vogel, H. 2015. Molecular mechanisms of insect adaptation to plant secondary compounds. Current Opinion in Insect Science, 8, 8-14.

Hemming, J. D. C., \& Lindroth, R. L. 1999. Effects of light and nutrient availability on aspen: Growth, phytochemistry, and insect performance. Journal of Chemical Ecology, 25(7), 1687-1714.

Henry L, Peccoud J, Simon J-C, Hadfield J, Maiden M, Ferrari J and Godfray H. 2013. Horizontally transmitted symbionts and host colonization of ecological niches. Current Biology 23, 1713-1717.

Hervé, M. R., Delourme, R., Gravot, A., Marnet, N., Berardocco, S., \& Cortesero, A. M. 2014. Manipulating Feeding Stimulation to Protect Crops Against Insect Pests? Journal of Chemical Ecology, 40(11-12), 1220-1231.

Heyworth ER and Ferrari J. 2016. Heat stress affects facultative symbiont-mediated protection from a parasitoid wasp. PLOS ONE 11, 1-11.

Heyworth ER, Smee MR and Ferrari J. 2020. Aphid facultative symbionts aid recovery of their obligate symbiont and their host after heat stress. Frontiers in Ecology and Evolution 8, 56.

Himanen SJ, Nerg A-M, Nissinen A, Pinto DM, Stewart Jr CN, Poppy GM and Holopainen JK. 2009. Effects of elevated carbon dioxide and ozone on volatile terpenoid emissions and multitrophic communication of transgenic insecticidal oilseed rape (Brassica napus). New Phytologist 181, 174-186.

Hoffmann A. A., Chown S. L. and Clusella-Trullas S. 2013. Upper thermal limits in terrestrial ectotherms: how constrained are they?. Functional Ecology 27, 934-949.

Hol, W. H. G., Vrieling, K., \& Van Veen, J. A. 2003. Nutrients decrease pyrrolizidine alkaloid concentrations in Senecio jacobaea. New Phytologist, 158(1), 175-181. 
1680

1681

1682

1683

1684

1685

1686

1687

1688

1689

1690

1691

1692

1693

1694

1695

1696

1697

1698

1699

1700

1701

1702

1703

1704

1705

1706

1707

1708

1709

1710

1711

1712

1713

1714

1715

Holton MK, Lindroth RL and Nordheim EV. 2003. Foliar quality influences tree-herbivoreparasitoid interactions: effects of elevated $\mathrm{CO} 2, \mathrm{O} 3$, and plant genotype. Oecologia 137, 233-244.

Huang, D., Haack, R. A., \& Zhang, R. 2011. Does global warming increase establishment rates of invasive alien species? a centurial time series analysis. PLOS ONE, 6(9), e24733.

Hui, C., Richardson, D. M., Landi, P., Minoarivelo, H. O., Roy, H. E., Latombe, G., Jing, X., CaraDonna, P. J., Gravel, D., Beckage, B. \& Molofsky, J. 2021. Trait positions for elevated invasiveness in adaptive ecological networks. Biological Invasions.

Ibrahim, M. A., Stewart-Jones, A., Pulkkinen, J., Poppy, G. M., \& Holopainen, J. K. 2008. The influence of different nutrient levels on insect-induced plant volatiles in $\mathrm{Bt}$ and conventional oilseed rape plants. Plant Biology, 10(1), 97-107.

Iltis C, Moreau J, Manière C, Thiéry D, Delbac L and Louâpre P. 2020. Where you come from matters: temperature influences host-parasitoid interaction through parental effects. Oecologia 192, 853-863.

IPBES, 2019. Summary for Policymakers of the Global Assessment Report of the Intergovernmental Science-Policy Platform on Biodiversity and Ecosystem Services Secretariat of the Intergovernmental Science-Policy Platform on Biodiversity and Ecosystem Services, Bonn, Germany.

IPCC, 2021: Climate Change 2021: The Physical Science Basis. Contribution of Working Group I to the Sixth Assessment Report of the Intergovernmental Panel on Climate Change [Masson-Delmotte, V., P. Zhai, A. Pirani, S. L. Connors, C. Péan, S. Berger, N. Caud, Y. Chen, L. Goldfarb, M. I. Gomis, M. Huang, K. Leitzell, E. Lonnoy, J. B. R. Matthews, T. K. Maycock, T. Waterfield, O. Yelekçi, R. Yu and B. Zhou (eds.)]. Cambridge University Press. In Press.

Jamieson MA, Burkle LA, Manson JS, Runyon JB, Trowbridge AM and Zientek J. 2017. Global change effects on plant-insect interactions: the role of phytochemistry. Current Opinion in Insect Science 23, 70-80.

Jeffs CT and Lewis OT. 2013. Effects of climate warming on host-parasitoid interactions. Ecological Entomology 38, 209-218.

Jerbi-Elayed M, Lebdi-Grissa K, Le Goff G and Hance T. 2015. Influence of temperature on flight, walking and oviposition capacities of two aphid parasitoid species (Hymenoptera: Aphidiinae). Journal of Insect Behavior 28, 157-166.

Jervis M.A., \& Kidd N. 1996. Insect Natural Enemies - Practical approaches to their study and evaluation / M.A. Jervis / Springer. Springer Netherlands.

Jervis, M. A. 2005. Insects as natural enemies: A practical perspective. In Insects As Natural Enemies: A Practical Perspective. Springer Netherlands. 
1716

1717

1718

1719

1720

1721

1722

1723

1724

1725

1726

1727

1728

1729

1730

1731

1732

1733

1734

1735

1736

1737

1738

1739

1740

1741

1742

1743

1744

1745

1746

1747

1748

1749

1750

1751

Jiang J-X, Yang J-H, Ji X-Y, Zhang H and Wan N-F. 2018. Experimental temperature elevation promotes the cooperative ability of two natural enemies in the control of insect herbivores. Biological Control 117, 52-62.

Johns, C. V., \& Hughes, L. 2002. Interactive effects of elevated CO2 and temperature on the leaf-miner Dialectica scalariella Zeller (Lepidoptera: Gracillariidae) in Paterson's Curse, Echium plantagineum (Boraginaceae). Global Change Biology, 8(2), 142-152.

Johnson, S. N., Staley, J. T., McLeod, F. A. L., \& Hartley, S. E. 2011. Plant-mediated effects of soil invertebrates and summer drought on above-ground multitrophic interactions. Journal of Ecology, 99(1), 57-65.

Jonsson, M., Buckley, H. L., Case, B. S., Wratten, S. D., Hale, R. J., \& Didham, R. K. 2012. Agricultural intensification drives landscape-context effects on host-parasitoid interactions in agroecosystems. Journal of Applied Ecology, 49(3), 706-714.

Kampfraath, A. A., Giesen, D., van Gestel, C. A. M., \& Le Lann, C. 2017. Pesticide stress on plants negatively affects parasitoid fitness through a bypass of their phytophage hosts. Ecotoxicology, 26(3), 383-395.

Kankaanpää T, Vesterinen E, Hardwick B, Schmidt NM, Andersson T, Aspholm PE, Barrio IC, Beckers N, Bêty J, Birkemoe T, DeSiervo M, Drotos KHI, Ehrich D, Gilg O, Gilg V, Hein N, Høye TT, Jakobsen KM, Jodouin C, Jorna J, Kozlov MV, Kresse J-C, Leandri-Breton D-J, Lecomte N, Loonen M, Marr P, Monckton SK, Olsen M, Otis J-A, Pyle M, Roos RE, Raundrup K, Rozhkova D, Sabard B, Sokolov A, Sokolova N, Solecki AM, Urbanowicz C, Villeneuve C, Vyguzova E, Zverev V and Roslin T. 2020. Parasitoids indicate major climateinduced shifts in arctic communities. Global Change Biology 26, 6276-6295.

Kansman JT, Ward M, LaFond H and Finke DL. 2021. Effects of plant stress on aphidparasitoid interactions: drought improves aphid suppression. Environmental Entomology.

Karowe, D. N., \& Martin, M. M. 1989. The effects of quantity and quality of diet nitrogen on the growth, efficiency of food utilization, nitrogen budget, and metabolic rate of fifth-instar Spodoptera eridania larvae (Lepidoptera: Noctuidae). Journal of Insect Physiology, 35(9), 699-708

Karp, D., Chaplin-Kramer, R. Meehan, T. D. et al. 2018. Crop pests and predators exhibit inconsistent responses to surrounding landscape composition. PNAS. 115 (33) E7863E7870.

Kester, K. M., \& Barbosa, P. 1991. Behavioral and ecological constraints imposed by plants on insect parasitoids: Implications for biological control. Biological Control, 1(2), 94-106.

Khan, M. A., \& Ruberson, J. R. 2017. Lethal effects of selected novel pesticides on immature stages of Trichogramma pretiosum (Hymenoptera: Trichogrammatidae). Pest Management Science, 73(12), 2465-2472. 
1752

1753

1754

1755

1756

1757

1758

1759

1760

1761

1762

1763

1764

1765

1766

1767

1768

1769

1770

1771

1772

1773

1774

1775

1776

1777

1778

1779

1780

1781

1782

1783

1784

1785

1786

Krauss, J., Härri, S. A., Bush, L., Husi, R., Bigler, L., Power, S. A., \& Müller, C. B. 2007. Effects of fertilizer, fungal endophytes and plant cultivar on the performance of insect herbivores and their natural enemies. Functional Ecology, 21(1), 107-116.

Krischik, V., Rogers, M., Gupta, G., \& Varshney, A. 2015. Soil-applied imidacloprid translocates to ornamental flowers and reduces survival of adult coleomegilla maculata, harmonia axyridis, and hippodamia convergens lady beetles, and larval danaus plexippus and vanessa cardui butterflies. PLOS ONE, 10(3).

Lakeman-Fraser, P., \& Ewers, R. M. 2014. Untangling interactions: Do temperature and habitat fragmentation gradients simultaneously impact biotic relationships? Proceedings of the Royal Society B: Biological Sciences, 281(1787).

Laliberté, E., Wells, J. A., Declerck, F., Metcalfe, D. J., Catterall, C. P., Queiroz, C., Aubin, I., Bonser, S. P., Ding, Y., Fraterrigo, J. M., McNamara, S., Morgan, J. W., Merlos, D. S., Vesk, P. A., \& Mayfield, M. M. 2010. Land-use intensification reduces functional redundancy and response diversity in plant communities. Ecology Letters, 13(1), 76-86.

Lann, C. cile Le, Baaren, J. Van, \& Visser, B. 2021. Dealing with predictable and unpredictable temperatures in a climate change context: The case of parasitoids and their hosts. In Journal of Experimental Biology (Vol. 224, Issue Suppl_1). Company of Biologists Ltd.

Larsen, A. E., \& Noack, F. 2021. Impact of local and landscape complexity on the stability of field-level pest control. Nature Sustainability, 4(2), 120-128.

LaSalle, J. 1993. Parasitic Hymenoptera, biological control and biodiversity. In Hymenoptera and Biodiversity. CAB International.

Letourneau, D. K., Bothwell Allen, S. G., \& Stireman, J. O. 2012. Perennial habitat fragments, parasitoid diversity and parasitism in ephemeral crops. Journal of Applied Ecology, 49(6), 1405-1416.

Liu Y, Dong J, Chi B and Liu Y. 2016. Thermal activity thresholds of parasitoids Aphidius avenae and Aphidius gifuensis (Hymenoptera: Braconidae): implications for their efficacy as biological control agents in the Same location. Florida Entomologist 99, 691-695.

Lohaus, K., Vidal, S., \& Thies, C. 2013. Farming practices change food web structures in cereal aphid-parasitoid-hyperparasitoid communities. Oecologia. 2013; 171(1): 249-259.

Longley, M., \& Jepson, P. C. 1996. Effects of honeydew and insecticide residues on the distribution of foraging aphid parasitoids under glasshouse and field conditions. Entomologia Experimentalis et Applicata, 81(2), 189-198.

Longley, M., Jepson, P. C., Izquierdo, J., \& Sotherton, N. 1997. Temporal and spatial changes in aphid and parasitoid populations following applications of deltamethrin in winter wheat. Entomologia Experimentalis et Applicata, 83(1), 41-52. 
1787

1788

1789

1790

1791

1792

1793

1794

1795

1796

1797

1798

1799

1800

1801

1802

1803

1804

1805

1806

1807

1808

1809

1810

1811

1812

1813

1814

1815

1816

1817

1818

1819

1820

1821

1822

1823

Lopez-Nunez, F. A., Heleno, R. H., Ribeiro, S., Marchante, H. \& Marchante, E. 2017. Fourtrophic level food webs reveal the cascading impacts of an invasive plant targeted for biocontrol. Ecology, 98, 782-793.

Lou, Y., \& Baldwin, I. T. 2004. Nitrogen supply influences herbivore-induced direct and indirect defenses and transcriptional responses in Nicotiana attenuata. Plant Physiology, 135(1), 496-506.

Lu, Y., Wu, K., Jiang, Y., Guo, Y., \& Desneux, N. 2012. Widespread adoption of Bt cotton and insecticide decrease promotes biocontrol services. Nature, 487(7407), 362-365.

Lurgi, M., Galiana, N., Lopez, B. C., Joppa, L. N. \& Montoya, J. M. 2014. Network complexity and species traits mediate the effects of biological invasions on dynamic food webs. Frontiers in Ecology and Evolution, 2.

Mackay KD, Gross CL and Ryder DS. 2020. Increased reproductive success through parasitoid release at a range margin: Implications for range shifts induced by climate change. Journal of Biogeography 47, 1041-1055.

Macfadyen, S., Gibson, R., Polaszek, A., Morris, R. J., Craze, P. G., Planqué, R., Symondson, W. O. C. \& Memmott, J. 2009. Do differences in food web structure between organic and conventional farms affect the ecosystem service of pest control? Ecology Letters, 12, 229238.

Mack, R. N., Simberloff, D., Mark Lonsdale, W., Evans, H., Clout, M. \& Bazzaz, F. A. 2000. Biotic invasions: causes, epidemiology, global consequences, and control. Ecol. Appl., 10, 689-710.

Martin, E. A., Seo, B., Park, C. R., Reineking, B., \& Steffan-Dewenter, I. 2016. Scaledependent effects of landscape composition and configuration on natural enemy diversity, crop herbivory, and yields. Ecological Applications, 26(2), 448-462.

Martini $X$ and Stelinski LL. 2017. Drought stress affects response of phytopathogen vectors and their parasitoids to infection- and damage-induced plant volatile cues. Ecological Entomology 42, 721-730.

Martorana, L., Foti, M. C., Rondoni, G., Conti, E., Colazza, S. \& Peri, E. 2017. An invasive insect herbivore disrupts plant volatile-mediated tritrophic signalling. Journal of Pest Science, 90, 1079-1085.

Matlock, R. B., \& De La Cruz, R. 2002. An inventory of parasitic Hymenoptera in banana plantations under two pesticide regimes. Agriculture, Ecosystems and Environment, 93(13), 147-164.

Mattson, W. J. 1980. Herbivory in Relation to Plant Nitrogen Content. Annual Review of Ecology and Systematics, 11(1), 119-161.

Mcneill S., \& Southwood T. R. E. 1978. The role of nitrogen in the development of insect-plant relationships. Biochemical Aspects of Plant and Animal Coevolution, 77-98. 
Menéndez R, Gonzalaz-Megias A, Lewis OT, Shaw MR and Thomas CD. 2008. Escape from natural enemies during climate-driven range expansion: a case study. Ecological Entomology 33, 413-421.

Milonas, P. G., Partsinevelos, G., \& Kapranas, A. 2021. Susceptibility of different developmental stages of Trichogramma parasitoids to insecticides commonly used in the Mediterranean olive agroecosystem. Bulletin of Entomological Research, 111(3), 301-306.

Mohammed, A. A. A. H., Desneux, N., Monticelli, L. S., Fan, Y., Shi, X., Guedes, R. N. C., \& Gao, X. 2019. Potential for insecticide-mediated shift in ecological dominance between two competing aphid species. Chemosphere, 226, 651-658.

Moiroux J, Brodeur $J$ and Boivin G. 2014. Sex ratio variations with temperature in an egg parasitoid: behavioural adjustment and physiological constraint. Animal Behaviour 91, 6166.

Monticelli, L. S., Nguyen, L. T. H., Amiens-Desneux, E., Luo, C., Lavoir, A., Gatti, J.-L., \& Desneux, N. 2019. The preference-performance relationship as a means of classifying parasitoids according to their specialization degree. Evolutionary Applications, 12(8), 1626-1640.

Monticelli, L. S., Koutsovoulos, G., Lasserre, A., Amiens-Desneux, E., Lavoir, A.-V., Harwood, J. D., \& Desneux, N. 2021. Impact of host and plant phylogenies on parasitoid host range. Biological Control, 104729.

Monticelli, L. S., Desneux, N., \& Heimpel, G. E. 2021. Parasitoid-mediated indirect interactions between unsuitable and suitable hosts generate apparent predation in microcosm and modeling studies. Ecology and Evolution, 11(6), 2449-2460.

Montllor CB, Maxmen A and Purcell AH. 2002. Facultative bacterial endosymbionts benefit pea aphids Acyrthosiphon pisum under heat stress. Ecological Entomology 27, 189-195.

Moon, D. C., \& Stiling, P. 2002. The effects of salinity and nutrients on a tritrophic salt-marsh system. Ecology, 83(9), 2465-2476.

Moon, D. C., \& Stiling, P. 2000. Relative importance of abiotically induced direct and indirect effects on a salt-marsh herbivore. Ecology, 81(2), 470-481.

Moore ME, Hill CA and Kingsolver JG. 2021. Differing thermal sensitivities in a host-parasitoid interaction: High, fluctuating developmental temperatures produce dead wasps and giant caterpillars. Functional Ecology 35, 675-685.

Moore ME, Kester KM and Kingsolver JG. 2020. Rearing temperature and parasitoid load determine host and parasitoid performance in Manduca sexta and Cotesia congregata. Ecological Entomology 45, 79-89.

Moreno-Delafuente A, Viñuela E, Fereres A, Medina P and Trebicki P. 2021. Combined effects of elevated $\mathrm{CO} 2$ and temperature on multitrophic interactions involving a parasitoid of plant virus vectors. BioControl66, 307-319. 
1861

Morse DH. 2021. Rapid phenological change differs across four trophic levels over 15 years. Oecologia : doi:https://doi.org/10.1007/s00442-021-04938-3.

Muller CB, Adriaanse ICT, Belshaw R, Godfray HCJ, 1999. The structure of an aphidparasitoid community. J Anim Ecol 68,346-370.

Mullin, C., \& Croft, B. 1985. An update on development of selective pesticides favoring arthropod natural enemies. Academic Press.

Munir S, Dosdall LM, O'Donovan JT and Keddie A. 2016. Diadegma insulare development is altered by Plutella xylostella reared on water-stressed host plants. Journal of Applied Entomology 140, 364-375.

Myers, S. S., Zanobetti, A., Kloog, I., Huybers, P., Leakey, A. D. B., Bloom, A. J., Carlisle, E., Dietterich, L. H., Fitzgerald, G., Hasegawa, T., Holbrook, N. M., Nelson, R. L., Ottman, M. J., Raboy, V., Sakai, H., Sartor, K. A., Schwartz, J., Seneweera, S., Tausz, M., \& Usui, Y. 2014. Increasing CO2 threatens human nutrition. Nature 2014 510:7503, 510(7503), 139_ 142.

Nelson, K. S., \& Burchfield, E. K. 2021. Landscape complexity and US crop production. Nature Food, 2(5), 330-338.

Nguyen, L. T. H., Monticelli, L. S., Desneux, N., Metay-Merrien, C., Amiens-Desneux, E., \& Lavoir, A. V. 2018. Bottom-up effect of water stress on the aphid parasitoid aphidius ervi. Entomologia Generalis, 38(1), 15-27.

Ode PJ. 2006. Plant chemistry and natural enemy fitness: effects on herbivore and natural enemy interactions. Annual Review of Entomology 51, 163-185.

Ode PJ, Johnson SN and Moore BD. 2014. Atmospheric change and induced plant secondary metabolites - are we reshaping the building blocks of multi-trophic interactions? Current Opinion in Insect Science 5, 57-65.

Ohta, I., \& Takeda, M. 2015. Acute toxicities of 42 pesticides used for green peppers to an aphid parasitoid, Aphidius gifuensis (Hymenoptera: Braconidae), in adult and mummy stages. Applied Entomology and Zoology, 50(2), 207-212.

Olfert O, Haye T, Weiss R, Kriticos D and Kuhlmann U. 2016. Modelling the potential impact of climate change on future spatial and temporal patterns of biological control agents, Peristenus digoneutis (Hymenoptera: Braconidae) as a case study. Canadian Entomologist $148,579$.

Oliver KM, Russell JA, Moran NA and Hunter MS. 2003. Facultative bacterial symbionts in aphids confer resistance to parasitic wasps. Proceedings of the National Academy of Sciences 100, 1803-1807.

Oliver KM, Smith AH and Russell JA. 2014. Defensive symbiosis in the real world - advancing ecological studies of heritable, protective bacteria in aphids and beyond. Functional Ecology 28, 341-355. 
1898

Pantel, J. H., Bohan, D. A., Calcagno, V., David, P., Duyck, P. F., Kamenova, S., Loeuille, N., Mollot, G., Romanuk, T. N., Thébault, E., Tixier, P., \& Massol, F. 2017. 14 Questions for Invasion in Ecological Networks. Advances in Ecological Research, 56, 293-340.

Paudel, J. R., Amirizian, A., Krosse, S., Giddings, J., Ismail, S. A. A., Xia, J., Gloer, J. B., van Dam, N. M., \& Bede, J. C. 2016. Effect of atmospheric carbon dioxide levels and nitrate fertilization on glucosinolate biosynthesis in mechanically damaged Arabidopsis plants. BMC Plant Biology, 16(1).

Pecl, G. T., Araújo, M. B., Bell, J. D., Blanchard, J., Bonebrake, T. C., Chen, I. C., Clark, T. D., Colwell, R. K., Danielsen, F., Evengård, B., Falconi, L., Ferrier, S., Frusher, S., Garcia, R. A., Griffis, R. B., Hobday, A. J., Janion-Scheepers, C., Jarzyna, M. A., Jennings, S., ... Williams, S. E. 2017. Biodiversity redistribution under climate change: Impacts on ecosystems and human well-being. In Science. 355, 6332.

Pekas, A., \& Wäckers, F. L. 2020. Bottom-up Effects on Tri-trophic Interactions: Plant Fertilization Enhances the Fitness of a Primary Parasitoid Mediated by Its Herbivore Host. Journal of Economic Entomology, 113(6), 2619-2626.

Pendergrass AG, Knutti R, Lehner F, Deser C and Sanderson BM. 2017. Precipitation variability increases in a warmer climate. Scientific Reports. 7, 17966.

Peralta, G., Frost, C. M., Rand, T. A., Didham, R. K. \& Tylianakis, J. M. 2014. Complementarity and redundancy of interactions enhance attack rates and spatial stability in host-parasitoid food webs. Ecology, 95, 1888-1896.

Pimm, S. L., \& Raven, P. 2000. Biodiversity - Extinction by numbers. Nature, 403(6772), 843845.

Pinheiro, L. A., Dáder, B., Wanumen, A. C., Pereira, J. A., Santos, S. A. P., \& Medina, P. 2020. Side effects of pesticides on the olive fruit fly parasitoid psyttalia concolor (Szépligeti): A review. In Agronomy. 10(11), 1755.

Pinto DM, Blande JD, Nykänen R, Dong W-X, Nerg A-M and Holopainen JK. 2007. Ozone degrades common herbivore-induced plant volatiles: does this affect herbivore prey location by predators and parasitoids?. Journal of Chemical Ecology 33, 683-694.

Pintureau B and Bolland P. 2001. A Trichogramma species showing a better adaptation to high temperature than its symbionts. Biocontrol Science and Technology 11, 13-20.

Plećaš, M., Gagić, V., Janković, M., Petrović-Obradović, O., Kavallieratos, N. G., Tomanović, Ž., Thies, C., Tscharntke, T., \& Ćetković, A. 2014. Landscape composition and configuration influence cereal aphid-parasitoid-hyperparasitoid interactions and biological control differentially across years. Agriculture, Ecosystems and Environment, 183, 1-10.

Pocock MJO and Evans DM. 2014. The success of the horse-chestnut leaf-miner, Cameraria ohridella, in the UK revealed with hypothesis-led citizen science. PLOS ONE 9, 1-9. 
1934

1935

1936

1937

1938

1939

1940

1941

1942

1943

1944

1945

1946

1947

1948

1949

1950

1951

1952

1953

1954

1955

1956

1957

1958

1959

1960

1961

1962

1963

1964

1965

1966

1967

1968

1969

Pöyry J, Leinonen R, Söderman G, Nieminen M, Heikkinen RK and Carter TR. 2011. Climateinduced increase of moth multivoltinism in boreal regions. Global Ecology and Biogeography 20, 289-298.

Preedy KF, Chaplain MAJ, Leybourne DJ, Marion G and Karley AJ. 2020. Learning-induced switching costs in a parasitoid can maintain diversity of host aphid phenotypes although biocontrol is destabilized under abiotic stress. Journal of Animal Ecology 89, 1216-1229.

Prudic, K. L., Oliver, J. C., \& Bowers, M. D. 2005. Soil nutrient effects on oviposition preference, larval performance, and chemical defense of a specialist insect herbivore. Oecologia, 143(4), 578-587.

Ragsdale DW, Landis DA, Brodeur J, Heimpel GE, Desneux N. 2011. Ecology and management of the soybean aphid in North America. Annu Rev Entomol 56,375-399.

Rakes, M., Pasini, R. A., Morais, M. C., Araújo, M. B., de Bastos Pazini, J., Seidel, E. J., Bernardi, D., \& Grützmacher, A. D. 2021. Pesticide selectivity to the parasitoid Trichogramma pretiosum: A pattern 10-year database and its implications for Integrated Pest Management. Ecotoxicology and Environmental Safety, 208.

Rand, T. A., \& Tscharntke, T. 2007. Contrasting effects of natural habitat loss on generalist and specialist aphid natural enemies. Oikos, 116(8), 1353-1362.

Romo CM and Tylianakis JM. 2013. Elevated Temperature and Drought Interact to Reduce Parasitoid Effectiveness in Suppressing Hosts. PLOS ONE 8, 1-9.

Röse, U. S. R., Joe Lewis, W., \& Tumlinson, J. H. 1998. Specificity of systemically released cotton volatiles as attractants for specialist and generalist parasitic wasps. Journal of Chemical Ecology, 24(2), 303-319.

Roth SK and Lindroth RL. 1995. Elevated atmospheric CO2: effects on phytochemistry, insect performance and insect-parasitoid interactions. Global Change Biology 1, 173-182.

Sala, O. E., Chapin, F. S., Armesto, J. J., Berlow, E., Bloomfield, J., Dirzo, R., Huber-Sanwald, E., Huenneke, L. F., Jackson, R. B., Kinzig, A., Leemans, R., Lodge, D. M., Mooney, H. A., Oesterheld, M., Poff, N. L. R., Sykes, M. T., Walker, B. H., Walker, M., \& Wall, D. H. (2000). Global biodiversity scenarios for the year 2100. In Science. 287(5459), 1770-1774.

Salazar-Mendoza P, Peralta-Aragón I, Romero-Rivas L, Salamanca J and Rodriguez-Saona C. 2021. The abundance and diversity of fruit flies and their parasitoids change with elevation in guava orchards in a tropical Andean forest of Peru, independent of seasonality. PLOS ONE 16, 1-21.

Salcido DM, Forister ML, Garcia Lopez H and Dyer LA. 2020. Loss of dominant caterpillar genera in a protected tropical forest. Scientific Reports 10, 422.

Sarfraz, M., Dosdall, L. M., \& Keddie, B. A. 2009. Host plant nutritional quality affects the performance of the parasitoid Diadegma insulare. Biological Control, 51(1), 34-41. 
1970

1971

1972

1973

1974

1975

1976

1977

1978

1979

1980

1981

1982

1983

1984

1985

1986

1987

1988

1989

1990

1991

1992

1993

1994

1995

1996

1997

1998

1999

2000

2001

2002

2003

2004

2005

Schellhorn, N. A., Gagic, V., \& Bommarco, R. 2015. Time will tell: resource continuity bolsters ecosystem services. Trends in Ecology \& Evolution, 30(9).

Schmelz, E. A., Alborn, H. T., Engelberth, J., \& Tumlinson, J. H. 2003. Nitrogen deficiency increases volicitin-induced volatile emission, jasmonic acid accumulation, and ethylene sensitivity in maize. Plant Physiology, 133(1), 295-306.

Schooler, S. S., De Barro, P., \& Ives, A. R. 2011. The potential for hyperparasitism to compromise biological control: Why don't hyperparasitoids drive their primary parasitoid hosts extinct? Biological Control, 58(3), 167-173.

Schoonhoven, L. M., Loon, J. J. A. van., \& Dicke, M. 2005. Insect-plant biology. Oxford University Press.

Schreven SJJ, Frago E, Stens A, de Jong PW and van Loon JJA. 2017. Contrasting effects of heat pulses on different trophic levels, an experiment with a herbivore-parasitoid model system. PLOS ONE 12, 1-13.

Schuler, T. H., Potting, R. P. J., Denholm, I., \& Poppy, G. M. 1999. Parasitoid behaviour and Bt plants. Nature. 400(6747), 825-826.

Schulze-Sylvester M and Reineke A. 2019. Elevated CO2 levels impact fitness traits of vine mealybug Planococcus ficus Signoret, but not its parasitoid Leptomastix dactylopii Howard. Agronomy 9, 326.

Schweiger, O., Biesmeijer, J. C., Bommarco, R., Hickler, T., Hulme, P. E., Klotz, S., Kühn, I., Moora, M., Nielsen, A., Ohlemüller, R., Petanidou, T., Potts, S. G., Pyšek, P., Stout, J. C., Sykes, M. T., Tscheulin, T., Vilà, M., Walther, G. R., Westphal, C., ... Settele, J. 2010. Multiple stressors on biotic interactions: How climate change and alien species interact to affect pollination. Biological Reviews. 85(4), 777-795.

Self, L. S., Guthrie, F. E., \& Hodgson, E. 1964. Adaptation of tobacco hornworms to the ingestion of nicotine. Journal of Insect Physiology, 10(6), 907-914.

Senior VL, Evans LC, Leather SR, Oliver TH and Evans KL. 2020. Phenological responses in a sycamore-aphid-parasitoid system and consequences for aphid population dynamics: A 20 year case study. Global Change Biology 26, 2814-2828.

Serra, A. A., Couée, I., Renault, D., Gouesbet, G., \& Sulmon, C. 2015. Metabolic profiling of Lolium perenne shows functional integration of metabolic responses to diverse subtoxic conditions of chemical stress. Journal of Experimental Botany, 66(7), 1801-1816.

Shehzad, M., Gulzar, A., Staley, J. T., \& Tariq, M. 2021. The effects of drought stress and type of fertiliser on generalist and specialist herbivores and their natural enemies. Annals of Applied Biology, 178(2), 377-386.

Sinclair BJ, Marshall KE, Sewell MA, Levesque DL, Willett CS, Slotsbo S, Dong Y, Harley CDG, Marshall DJ, Helmuth BS and Huey RB. 2016. Can we predict ectotherm responses 
to climate change using thermal performance curves and body temperatures?. Ecology Letters 19, 1372-1385.

Singer A, Travis JMJ and Johst K. 2013. Interspecific interactions affect species and community responses to climate shifts. Oikos 122, 358-366.

Smith, R. H., \& Shaw, M. R. 1980. Haplodiploid sex ratios and the mutation rate. Nature, 287(5784), 728-729.

Smith-Ramesh, L. M., Moore, A. C. \& Schmitz, O. J. 2017. Global synthesis suggests that food web connectance correlates to invasion resistance. Global Change Biology, 23, 465473.

Stacey DA and Fellowes MDE. 2002. Influence of elevated CO2 on interspecific interactions at higher trophic levels. Global Change Biology 8, 668-678.

Stapel, J. O., Cortesero, A. M., \& Lewis, W. J. 2000. Disruptive sublethal effects of insecticides on biological control: Altered foraging ability and life span of a parasitoid after feeding on extrafloral nectar of cotton treated with systemic insecticides. Biological Control, 17(3), 243-249.

Stiling P, Rossi AM, Hungate B, Dijkstra P, Hinkle CR, Knott III WM and Drake B. 1999. Decreased leaf-miner abundance in elevated CO2: Reduced leaf quality and increased parasitoid attack. Ecological Applications 9, 240-244.

Stiling, P., \& Moon, D. C. 2005. Quality or quantity: The direct and indirect effects of host plants on herbivores and their natural enemies. Oecologia, 142(3), 413-420.

Stireman JO, Dyer LA, Janzen DH, Singer MS, Lill JT, Marquis RJ, Ricklefs RE, Gentry GL, Hallwachs W, Coley PD, Barone JA, Greeney HF, Connahs H, Barbosa P, Morais HC and Diniz IR. 2005. Climatic unpredictability and parasitism of caterpillars: Implications of global warming. Proceedings of the National Academy of Sciences 102, 17384-17387.

Stoks R, Verheyen J, Van Dievel M and Tüzün N. 2017. Daily temperature variation and extreme high temperatures drive performance and biotic interactions in a warming world. Current Opinion in Insect Science 23, 35-42.

Stone, GN, Lohse, K, Nicholls, JA, Fuentes-Utrilla, P, Sinclair, F, Schönrogge, K, Csóka, G, Melika, G, Nieves-Aldrey, J-L, Pujade-Villar, J, Tavakoli, M, Askew, RR and Hickerson, MJ. 2012. Reconstructing Community Assembly in Time and Space Reveals Enemy Escape in a Western Palearctic Insect Community. Current Biology 22, 532-537.

Stout, M. J., Brovont, R. A., \& Duffey, S. S. 1998. Effect of nitrogen avilability on expression of constitutive and inducible chemical defenses in tomato, Lycopersicon esculentum. Journal of Chemical Ecology, 24(6), 945-963.

Sun Y-C, Yin J, Chen F-J, Wu G and Ge F. 2011. How does atmospheric elevated CO2 affect crop pests and their natural enemies? Case histories from China. Insect Science 18, 393400. 
2043

2044

2045

2046

2047

2048

2049

2050

2051

2052

2053

2054

2055

2056

2057

2058

2059

2060

2061

2062

2063

2064

2065

2066

2067

2068

2069

2070

2071

2072

2073

2074

2075

2076

2077

2078

Sun, R., Gols, R., Harvey, J. A., Reichelt, M., Gershenzon, J., Pandit, S. S., \& Vassão, D. G. 2020. Detoxification of plant defensive glucosinolates by an herbivorous caterpillar is beneficial to its endoparasitic wasp. Molecular Ecology, 29(20), 4014-4031.

Tack AJM, Gripenberg S, Roslin T, 2011. Can we predict indirect interactions from quantitative food webs? An experimental approach. J Anim Ecol 80,108-118.

Tappert, L., Pokorny, T., Hofferberth, J., \& Ruther, J. 2017. Sublethal doses of imidacloprid disrupt sexual communication and host finding in a parasitoid wasp. Scientific Reports, 7.

Tariq M, Wright DJ, Bruce TJA and Staley JT. 2013. Drought and root herbivory interact to alter the response of above-ground parasitoids to aphid infested plants and associated plant volatile signals. PLOS ONE 8, 1-12.

Tews, J., Brose, U., Grimm, V., Tielbörger, K., Wichmann, M. C., Schwager, M., \& Jeltsch, F. 2004. Animal species diversity driven by habitat heterogeneity/diversity: The importance of keystone structures. Journal of Biogeography. 31(1), 79-92.

Thierry M, Hrcek J and Lewis OT. 2019. Mechanisms structuring host-parasitoid networks in a global warming context: a review. Ecological Entomology 44, 581-592.

Thierry M, Pardikes NA, Lue C-H, Lewis OT and Hrcek J. 2021. Experimental warming influences species abundances in a Drosophila host community through direct effects on species performance rather than altered competition and parasitism. PLOS ONE 16, 1-15.

Thies, C., Haenke, S., Scherber, C., Bengtsson, J., Bommarco, R., Clement, L. W., Ceryngier, P., Dennis, C., Emmerson, M., Gagic, V., Hawro, V., Liira, J., Weisser, W. W., Winqvist, C., \& Tscharntke, T. 2011. The relationship between agricultural intensification and biological control: Experimental tests across Europe. Ecological Applications, 21(6), 2187-2196.

Thomson LJ, Macfadyen S and Hoffmann AA. 2010. Predicting the effects of climate change on natural enemies of agricultural pests. Biological Control 52, 296-306.

Thorpe, K. W., \& Barbosa, P. 1986. Effects of comsumption of high and low nicotine tobacco by Manduca sexta (Lepidoptera: Sphingidae) on survival of gregarious endoparasitoid Cotesia congregata (Hymenoptera: Braconidae). Journal of Chemical Ecology, 12(6), 1329-1337.

Timms, L. L., Walker, S. C. \& Smith, S. M. 2012. Establishment and dominance of an introduced herbivore has limited impact on native host-parasitoid food webs. Biological Invasions, 14, 229-244.

Tougeron K, Damien M, Le Lann C, Brodeur J and van Baaren J. 2018. Rapid Responses of Winter Aphid-Parasitoid Communities to Climate Warming. Frontiers in Ecology and Evolution 6, 173.

Tougeron, K., \& Tena, A. 2019. Hyperparasitoids as new targets in biological control in a global change context. Biological Control. 130, 164-171. 
2079

2080

2081

2082

2083

2084

2085

2086

2087

2088

2089

2090

2091

2092

2093

2094

2095

2096

2097

2098

2099

2100

2101

2102

2103

2104

2105

2106

2107

2108

2109

2110

2111

2112

2113

Trotta V, Forlano P, Falabella P, Battaglia D and Fanti P. 2018. The aphid Acyrthosiphon pisum exhibits a greater survival after a heat shock when parasitized by the wasp Aphidius ervi. Journal of Thermal Biology 72, 53-58.

Tscharntke, T., Klein, A. M., Kruess, A., Steffan-Dewenter, I., \& Thies, C. 2005. Landscape perspectives on agricultural intensification and biodiversity - Ecosystem service management. Ecology Letters. 8(8), 857-874.

Turlings TCJ, Tumlinson JH, Heath RR, Proveaux AT and Doolittle RE. 1991. Isolation and identification of allelochemicals that attract the larval parasitoid, Cotesia marginiventris (Cresson), to the microhabitat of one of its hosts. Journal of Chemical Ecology 17, 22352251.

Turlings, T. C. J., \& Benrey, B. 1998. Effects of plant metabolites on the behavior and development of parasitic wasps. Ecoscience, 5(3), 321-333.

Tylianakis, J. M., Didham, R. K., Bascompte, J., \& Wardle, D. A. 2008. Global change and species interactions in terrestrial ecosystems. Ecology Letters. 11(12), 1351-1363.

Tylianakis, J. M. \& Binzer, A. 2014. Effects of global environmental changes on parasitoidhost food webs and biological control. Biological Control, 75, 77-86.

Ulina, E. S., Rizali, A., Manuwoto, S., Pudjianto, \& Buchori, D. 2019. Does composition of tropical agricultural landscape affect parasitoid diversity and their host-parasitoid interactions? Agricultural and Forest Entomology, 21(3), 318-325.

Valladares G, Salvo A, Godfray H, 2001. Quantitative food webs of dipteran leafminers and their parasitoids in Argentina. Ecol Res 16,925-939.

Valls A, Kral-O'Brien K, Kopco J and Harmon JP. 2020. Timing alters how a heat shock affects a host-parasitoid interaction. Journal of Thermal Biology 90, 102596.

Van Asselen, S., \& Verburg, P. H. 2013. Land cover change or land-use intensification: Simulating land system change with a global-scale land change model. Global Change Biology, 19(12), 3648-3667.

van Emden, H. F. 1995. Host plant-Aphidophaga interactions. Agriculture, Ecosystems and Environment, 52(1), 3-11.

Vanbergen, A. J., Espíndola, A. \& Aizen, M. A. 2018. Risks to pollinators and pollination from invasive alien species. Nature Ecology \& Evolution, 2, 16-25.

Vanbergen, A. J., Aizen, M. A., Cordeau, S., Garibaldi, L. A., Garratt, M. P. D., KovácsHostyánszki, A., Lecuyer, L., Ngo, H. T., Potts, S. G., Settele, J., Skrimizea, E., \& Young, J. C. 2020. Transformation of agricultural landscapes in the Anthropocene: Nature's contributions to people, agriculture and food security. Advances in Ecological Research. 63, 193-253. 
2114 Vanderplanck M, Lapeyre B, Brondani M, Opsommer M, Dufay M, Hossaert-McKey M and 2115 Proffit M. 2021. Ozone pollution alters olfaction and behavior of pollinators. Antioxidants $2116 \quad 10,636$.

2117 Van Nouhuys S and Lei G. 2004. Parasitoid-host metapopulation dynamics: the causes and 2118 consequences of phenological asynchrony. Journal of Animal Ecology 73, 526-535.

2119 Veres, A., Petit, S., Conord, C., \& Lavigne, C. 2013. Does landscape composition affect pest 2120 abundance and their control by natural enemies? A review. Agriculture, Ecosystems and Environment. 166, 110-117.

Vianna, U. R., Pratissoli, D., Zanuncio, J. C., Lima, E. R., Brunner, J., Pereira, F. F., \& Serrão, J. E. 2009. Insecticide toxicity to Trichogramma pretiosum (Hymenoptera: Trichogrammatidae) females and effect on descendant generation. Ecotoxicology, 18(2).

Vuorinen T, Nerg A-M, Ibrahim M, Reddy G and Holopainen JK. 2004. Emission of Plutella xylostella-induced compounds from cabbages grown at elevated $\mathrm{CO} 2$ and orientation behavior of the natural enemies. Plant Physiology 135, 1984-1992.

Vyas, D. K., Paul, R. L., Gates, M. W., Kubik, T., Harvey, J. A., Kondratieff, B. C., \& Ode, P. J. 2020. Shared enemies exert differential mortality on two competing parasitic wasps. Basic and Applied Ecology, 47, 107-119.

Wade RN, Karley AJ, Johnson SN and Hartley SE. 2017. Impact of predicted precipitation scenarios on multitrophic interactions. Functional Ecology 31, 1647-1658.

Walls, R., Appel, H., Cipollini, M., \& Schultz, J. 2005. Fertility, root reserves and the cost of inducible defenses in the perennial plant Solanum carolinense. Journal of Chemical Ecology, 31(10), 2263-2288.

Walther, G. R., Post, E., Convey, P., Menzel, A., Parmesan, C., Beebee, T. J. C., Fromentin, J. M., Hoegh-Guldberg, O., \& Bairlein, F. 2002. Ecological responses to recent climate change. Nature. 416(6879), 389-395.

2139

Wang G-H, Wang X-X, Sun Y-C and Ge F. 2014. Impacts of elevated CO2 on Bemisia tabaci infesting Bt cotton and its parasitoid Encarsia formosa. Entomologia Experimentalis et Applicata 152, 228-237.

Wang, Q. L., \& Liu, T. X. 2016. Effects of three insect growth regulators on Encarsia formosa (Hymenoptera: Aphelinidae), an endoparasitoid of Bemisia tabaci (Hemiptera: Aleyrodidae). Journal of Economic Entomology, 109(6), 2290-2297. 2021. Exploring the potential for novel associations of generalist parasitoids for biological control of invasive woodboring beetles. Biocontrol, 66, 97-112. relation to plant growth stage and growth of Rhopalosiphum padi. Annals of Applied Biology, 111(3), 729-737. 
2151

2152

2153

2154

2155

2156

2157

2158

2159

2160

2161

2162

2163

2164

2165

2166

2167

2168

2169

2170

2171

2172

2173

2174

2175

2176

2177

2178

2179

2180

2181

2182

2183

2184

2185

2186

2187

Weinzierl, R. A. 2008. Integrating pesticides with biotic and biological control for arthropod pest management. In Integrated Pest Management: Concepts, Tactics, Strategies and Case Studies (pp. 179-191). Cambridge University Press.

Weldegergis BT, Zhu F, Poelman EH and Dicke M. 2015. Drought stress affects plant metabolites and herbivore preference but not host location by its parasitoids. Oecologia 177, 701-713.

Williams, T., Valle, J., \& Viñuela, E. 2003. Is the naturally derived insecticide Spinosad® compatible with insect natural enemies? In Biocontrol Science and Technology (Vol. 13, Issue 5, pp. 459-475).

Wilson, E. O. 1987. The Little Things That Run the World (The Importance and Conservation of Invertebrates). Biology, 1(4), 344-346.

Winter, T. R., \& Rostás, M. 2010. Nitrogen deficiency affects bottom-up cascade without disrupting indirect plant defense. Journal of Chemical Ecology, 36(6), 642-651.

With, K. A., \& Pavuk, D. M. 2019. Habitat configuration matters when evaluating habitat-area effects on host-parasitoid interactions. Wiley Online Library, 10(2).

Wittstock, U., Agerbirk, N., Stauber, E. J., Olsen, C. E., Hippler, M., Mitchell-Olds, T., Gershenzon, J., \& Vogel, H. 2004. Successful herbivore attack due to metabolic diversion of a plant chemical defense. Proceedings of the National Academy of Sciences, 101(14), 4859-4864.

Wu LH, Hoffmann AA and Thomson LJ. 2016. Trichogramma parasitoids for control of Lepidopteran borers in Taiwan: species, life-history traits and Wolbachia infections. Journal of Applied Entomology 140, 353-363.

Wu L-H, Hill MP, Thomson LJ and Hoffmann AA. 2018. Assessing the current and future biological control potential of Trichogramma ostriniae on its hosts Ostrinia furnacalis and Ostrinia nubilalis. Pest Management Science 74, 1513-1523.

Wu L-H, Hoffmann AA and Thomson LJ. 2016. Potential impact of climate change on parasitism efficiency of egg parasitoids: a meta-analysis of Trichogramma under variable climate conditions. Agriculture, Ecosystems \& Environment 231, 143-155.

Yan H-Y, Guo H-G, Sun Y-C and Ge F. 2020. Plant phenolics mediated bottom-up effects of elevated $\mathrm{CO} 2$ on Acyrthosiphon pisum and its parasitoid Aphidius avenae. Insect Science 27, 170-184.

Yuan JS, Himanen SJ, Holopainen JK, Chen F and Stewart CN J. 2009. Smelling global climate change: mitigation of function for plant volatile organic compounds. Trends in Ecology \& Evolution 24, 323-331.

Zhang, P., Zhang, X., Zhao, Y., Wei, Y., Mu, W., \& Liu, F. 2016. Effects of imidacloprid and clothianidin seed treatments on wheat aphids and their natural enemies on winter wheat. Pest Management Science, 72(6), 1141-1149. 
2188 Zhao, X., Reitz, S. R., Yuan, H., Lei, Z., Paini, D. R., \& Gao, Y. 2017. Pesticide-mediated 2189 interspecific competition between local and invasive thrips pests. Scientific Reports, 7(1), $2190 \quad 1-7$.

2191 Zhao, Z. H., Hui, C., He, D. H., \& Li, B. L. 2015. Effects of agricultural intensification on ability 2192 of natural enemies to control aphids. Scientific Reports, 5, 8024.

2193 Ziska, L. H., Blumenthal, D. M., Runion, G. B., Hunt, E. R., \& Diaz-Soltero, H. 2011. Invasive 2194 species and climate change: An agronomic perspective. Climatic Change. 105(1), 13-42. 2195 Züst, T., \& Agrawal, A. A. (2016). Population growth and sequestration of plant toxins along a 2196 gradient of specialization in four aphid species on the common milkweed Asclepias syriaca. 2197 Functional Ecology, 30(4), 547-556.

2198

2199

2200 